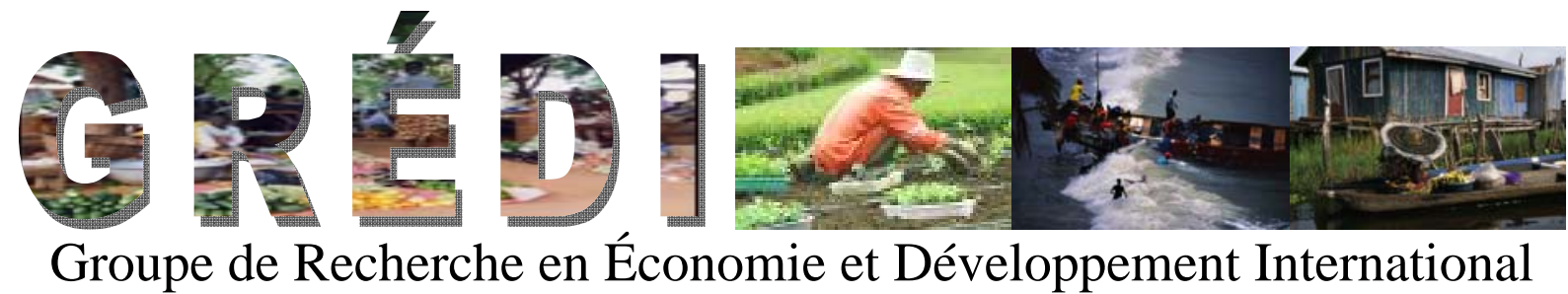

Cahier de recherche / Working Paper

09-18

Nominal Rigidities, Monetary Policy and Pigou Cycles

\author{
Stéphane Auray \\ Paul Gomme \\ Shen Guo
}




\title{
Nominal Rigidities, Monetary Policy and Pigou Cycles*
}

\author{
Stéphane Auray \\ EQUIPPE (EA 4018), Universités Lille Nord de France (ULCO), \\ GREDI, Université de Sherbrooke and CIRPÉE. \\ Paul Gomme \\ Concordia University and CIREQ \\ Shen Guo \\ China Academy of Public Finance and Public Policy, \\ Central University of Finance and Economics, Beijing, China.
}

07 July 2009

\begin{abstract}
A chief goal of the Pigou cycle literature is to generate a boom in response to news of a future increase in productivity, and a bust if this improvement does not in fact take place. We find that monetary policy can generate Pigou cycles in a two sector model with durables and non-durables, and nominal price rigidities - even when the Ramsey-optimal policy displays no such cycles. Estimated interest rate rules are a good fit to data simulated under the Ramsey policy, implying that policymakers could come close to replicating the Ramsey-optimal policy.
\end{abstract}

${ }^{*}$ Thanks to the participants of the 42nd Annual Meeting of the Canadian Economic Association and of the 4th Dynare conference for their valuable comments. 


\section{Introduction}

Recent interest in Pigou cycles - meaning economic fluctuations driven by signals of future productivity changes - was piqued by Beaudry and Portier (2004). One of the primary goal of this literature is to generate a boom in economic activity upon receipt of news of a future improvement in productivity (a "news shock"), followed by a bust when this news is not realized. ${ }^{1}$

This paper shows that monetary policy can lead to Pigou cycles. There are a number of model features that contribute to this result. First, in common with much of the Pigou cycle literature, there are two sectors: durables and non-durables. In the baseline model, durables and non-durables are strong complements in utility, a condition typical imposed in the Pigou cycle literature. The importance of this restriction is that consumer purchases of durables and non-durables will tend to move together. Second, as in Barsky, House and Kimball (2007), money demand is proportional to nominal purchases while money supply is exogenous. An advantage of this formulation of money demand is that it isolates the deleterious effects of relative price distortions while abstracting from the transactions distortions of money. Third, each sector is composed of a large number of monopolistically competitive intermediate goods producers. As in New Keynesian models, these intermediate goods firms reoptimize their prices as in Calvo (1983). An implication of the resulting nominal price rigidity is that intermediate goods producers are forward looking in their pricing behavior since the opportunity to reoptimize their prices has a Poisson arrival rate. In response to a positive non-durable sector news shock - a signal of a future productivity improvement in that sector - non-durable intermediate good producers lower their prices in anticipation of this future productivity improvement. ${ }^{2}$ As a result, the price of durables relative to that of non-durables rises. As pointed out by Barsky et al. (2007), this relative price is a primary determinant of durables purchases. Under a money supply rule, the nominal interest rate falls, although the

\footnotetext{
${ }^{1}$ An unrealized news shock can be thought of as a situation in which a conventional productivity shock exactly offsets the earlier news shock.

${ }^{2}$ Durable sector news shocks do not generate Pigou cycles.
} 
user cost of durables rises slightly. The net effect is that a non-durable sector news shock leads to an immediate boom in both the non-durable and durable goods sectors. When this news is completely offset by a conventional productivity shock - so that productivity does not end up changing - economic activity experiences a decline when the news shock is not realized. Nominal price rigidities are important in generating these results. A flexible price version of the baseline model has no change in the relative price of durables for the series of events just described since, in this case, this relative price is determined by actual productivity in the two sectors, and neither changes under this scenario.

We solve for the Ramsey-optimal policy of the baseline model; such a policy does not result in Pigou cycles. Under the Ramsey policy, a non-durable sector news shock results in a higher nominal interest rate whereas the exogenous money supply rule has a fall in the nominal interest rate. As a consequence, the user cost of durables rises more under the Ramsey policy than the exogenous money supply rule. Owing to the nominal rigidities, the relative price of durables follows a path indistinguishable from the exogenous money supply rule economy. The net result is a decline in durable purchases/production under the Ramsey policy. An implication of these results is that suboptimal monetary policies may generate Pigou cycles even when the optimal policy has no such cycles.

To drive this last point home, we solve a version of the model in which monetary policy is governed by an interest rate rule that responds weakly to inflation. We obtain essentially the same results as with an exogenous money supply, namely that such an interest rate rule generates Pigou cycles while the Ramsey policy does not. Furthermore, we derive these results for a parameterization of the model for which durables and non-durables are highly substitutable in consumption. Consequently, the weak inflation targeting case is of independent interest because it is one of the few cases in the literature in which Pigou cycles arise when durables and non-durables are substitutable in consumption.

Since Ramsey policies can be difficult to communicate to the public - after all, monetary policy ends up depending on the entire state of the economy - we estimate simple interest 
rate rules of the Taylor (1993) variety using data from the Ramsey economy. Like SchmittGrohé and Uribe (2004), such rules fit the artificial data well in the sense that they have a high $\mathrm{R}^{2}$. Solving and simulating the model under such estimated rules leads to impulseresponses that are quite similar to those obtained in the Ramsey economy. The fit of such rules is relatively insensitive to reducing the degree of nominal rigidities in the durable goods sector.

There are two important differences between our model and that of Beaudry and Portier (2004): the labor supply elasticity is finite in our model, infinite in their's; and they have declining marginal product of labor while it is constant in our model. That the flexible price version of our baseline model fails to deliver Pigou cycles can be traced to these two differences. We view this difference as a virtue since we can attribute the Pigou cycles in our baseline sticky price model as being due to the nominal rigidities. Likewise, the fact that the Ramsey-optimal policy does not exhibit Pigou cycles points to the importance of suboptimal policy in generating such cycles - at least in our model.

The framework in this paper is closely related to the recent development of two sector models with nominal rigidities (but no news shocks). Aoki (2001) studies optimal monetary policy responses to relative-price changes in a two-sector framework with a flexible-price sector and a sticky-price sector. Benigno (2004) evaluates monetary policy in a currency area where price rigidities may differ between countries. Barsky et al. (2007) explore the co-movements of non-durable and durable goods sectors in response to a monetary shock in a two sector model with nominal rigidities and long-lived durable goods. Erceg and Levin (2006) study optimal monetary policy in a two sector model with durable goods. They highlight the distinction between the non-durable and durable sectors in that the durable goods sector is much more interest-sensitive than the non-durable sector. Monacelli (2008, 2009) introduces collateral constraints into a two-sector model with non-durable and durable goods to study the co-movements in these two sectors in response to monetary policy shocks and optimal monetary issues. 
Other related papers include Christiano, Ilut, Motto and Rostagno (2008) and Jaimovich and Rebelo's (forthcoming) research on the possibility of generating expectation driven business cycles in one sector models. They succeed in generating booms and busts in consumption, investment and output by adding investment adjustment costs, variable utilization of capital and habit persistence into a standard one sector model. However, it is not that straightforward to get corresponding booms and busts of asset prices in their frameworks. Asset prices unexpectedly slump during the booms when all the other variables rise as expected. To solve this problem, Christiano et al. (2008) extend their model by adding sticky prices, sticky wages and standard Taylor-rule monetary policies. Compared with their frameworks, our model involves fewer real and nominal rigidities.

The remainder of this paper is organized as follows. Section 2 describes the economic environment and sets up the Ramsey optimal policy. The model is calibrated in Section 3. The central results of the paper are to be found in Section 4 where we report impulseresponses for a non-durable sector news shock for the baseline model, a version of the baseline model with flexible prices, and the model solved under the Ramsey policy. Section 5 contains the results of estimating a simple interest rate rule using model data simulated under the Ramsey policy. We also show that the results for the baseline model are sensitive to the elasticity of substitution between durables and non-durables. Section 5 finishes by presenting results for a weak inflation target rule. Section 6 concludes.

\section{Model}

The economy is composed of two sectors: a non-durable goods sector and a durable goods sector. Each sector has two types of firms: final goods producers that use sector-specific intermediate goods; and monopolistically competitive intermediate goods firms that each produces a differentiated product using labor. These intermediate goods firms determine their prices following a Calvo-type staggered price adjustment. Households supply labor to 
both sectors and derive utility from consumption of non-durable final goods and services of durable final goods. The central bank conducts monetary policy.

\subsection{Households}

The household purchases a non-durable good, $C_{t}$, and a durable good, $D_{t}$, in the market and derives its utility from the consumption of a final good, $X_{t}$. This final good is a CES composite of non-durable goods $C_{t}$ and durable goods $D_{t}$ :

$$
X_{t}=\left[(1-\alpha)^{\frac{1}{\eta}} C_{t}^{\frac{\eta-1}{\eta}}+\alpha^{\frac{1}{\eta}} D_{t}^{\frac{\eta-1}{\eta}}\right]^{\frac{\eta}{\eta-1}},
$$

where $\alpha$ governs the share of durable goods in the composite consumption index. $\eta>0$ is the elasticity of substitution between non-durable goods and durable goods. ${ }^{3}$

The household maximizes the following expected utility

$$
E_{0} \sum_{t=0}^{\infty} \beta^{t}\left(\ln \left(X_{t}\right)-v \frac{N_{t}^{1+\sigma}}{1+\sigma}\right)
$$

subject to constraint:

$$
P_{c, t} C_{t}+P_{d, t}\left[D_{t}-(1-\delta) D_{t-1}\right]+B_{t}+M_{t}=W_{t} N_{t}+R_{t-1} B_{t-1}+M_{t-1}+T_{t}+\Pi_{c, t}+\Pi_{d, t}
$$

where $N_{t}$ is total labor supply; $B_{t}$ is end-of-period $t$ nominal bond; and $R_{t-1}$ is the nominal interest rate on the bond stipulated at period $t-1 . M_{t}$ corresponds to the nominal money balances held and $W_{t}$ to the nominal wage. Labor is assumed to be perfectly mobile across sectors, implying that the nominal wage rate is common across sectors. $\Pi_{c, t}$ and $\Pi_{d, t}$ are dividends received from the ownership of intermediate firms in both sectors. Finally, $T_{t}$ is lump-sum transfers net of taxes.

In the baseline model, following Barsky et al. (2007), money demand is assumed to be

\footnotetext{
${ }^{3}$ In the case $\eta \rightarrow 0$, non-durable goods and durable goods are perfect complements; whereas if $\eta \rightarrow \infty$ the two goods are perfect substitutes.
} 
proportional to nominal purchases:

$$
M_{t}=P_{c, t} C_{t}+P_{d, t}\left[D_{t}-(1-\delta) D_{t-1}\right]
$$

The household chooses $\left\{N_{t}, B_{t}, D_{t}, C_{t}\right\}_{t=0}^{\infty}$ to maximize Eq. (2) subject to Eq. (3). Let $\lambda_{t}$ be the Lagrangian multiplier associated with constraint Eq. (3), and $U_{k, t}(k \in C, N, D)$ as the marginal utility of respective variable, first order conditions for household's decision problem read:

$$
\begin{aligned}
-\frac{U_{n, t}}{U_{c, t}} & =\frac{W_{t}}{P_{c, t}}, \\
q_{t} U_{c, t} & =U_{d, t}+\beta(1-\delta) E_{t}\left\{U_{c, t+1} q_{t+1}\right\}, \\
U_{c, t} & =\beta E_{t}\left\{R_{t} \frac{P_{c, t}}{P_{c, t+1}} U_{c, t+1}\right\},
\end{aligned}
$$

where $q_{t}=P_{d, t} / P_{c, t}$ is the relative price of the durable good. Eq. (5) links the real wage to the household's marginal rate of substitution between consumption and leisure. Eq. (6) requires that the household equates the marginal utility of current non-durable consumption to the marginal gain of durable services. The marginal gain of durable services includes two parts: (i) the direct utility gain of an additional unit of durables; (ii) the expected utility stemming from the consumption of the resale value of the durable purchased in previous period. Eq. (7) equates the cost of sacrificing one unit of consumption to the benefit of investing this money in the bond market. For future reference, the term $\beta U_{c, t+1} / U_{c, t}$ is defined as a stochastic discount factor $\Delta_{t}$.

Barsky et al. (2007) point out that one feature of the two sector model with long-lived durable goods is that the shadow price of the durable goods is approximately constant following a temporary shock, which can be shown in the following equation:

$$
\gamma_{t}=q_{t} U_{c, t}=U_{d, t}+\beta(1-\delta) E_{t}\left(U_{d, t+1}\right)+\beta^{2}(1-\delta)^{2} E_{t}\left(U_{d, t+2}\right)+\ldots
$$


where $\gamma_{t}$ is the shadow value of the durable goods. If durables are long-lasting, meaning that $\delta$ is close to zero, then the stock of durables relative to its investment flow is very high. Even large fluctuations in purchases of durable goods have only minor effects on the stock. The shadow value of durable goods will be roughly constant in the face of a news shock since news shocks only causes a temporary and modest deviation of the durable goods stock from the steady state. From Eq. (8), it is straightforward to show that the marginal utility of non-durable goods, and thus the consumption of non-durable goods are determined by the price of the durable good relative to the price of the non-durable good.

Eq. (6) can be rearranged as

$$
U_{d, t}=U_{c, t} \underbrace{\left\{q_{t}-\beta(1-\delta) E_{t}\left(\frac{U_{c, t+1}}{U_{c, t}} q_{t+1}\right)\right\}}_{\text {user cost }} .
$$

The cost of one unit of durable goods is $q_{t}$ units of the non-durable good. Next period, after depreciation, the remaining durable goods stock $1-\delta$ can be sold at relative price $q_{t+1}$. The user cost can be seen as its (relative) purchase price less the present value of resale revenue.

\section{$2.2 \quad$ Final Good Producers}

In each sector $j(j \in\{c, d\}$, where $c$ denotes the non-durable sector and $d$ denotes the durable sector), a perfectly competitive final good producer purchases $Y_{j, t}(i)$ units of intermediate good $i$. The production function that transforms intermediate goods into the final good is given by

$$
Y_{j, t}=\left[\int_{0}^{1} Y_{j, t}(i)^{\frac{\varepsilon_{j}-1}{\varepsilon_{j}}} d i\right]^{\frac{\varepsilon_{j}}{\varepsilon_{j}-1}} \quad\left(\varepsilon_{j}>1, \quad j \in c, d\right),
$$

where $\varepsilon_{j}$ is the elasticity of substitution between differentiated intermediate goods in sector $j$.

The demand function for intermediate good $i$ in sector $j$ can be derived from the following 
cost minimization problem: Choose $Y_{j, t}(i)$ to minimize

$$
\min \int_{0}^{1} P_{j, t}(i) Y_{j, t}(i) d i
$$

subject to

$$
\left[\int_{0}^{1} Y_{j, t}(i)^{\frac{\varepsilon_{j}-1}{\varepsilon_{j}}} d i\right]^{\frac{\varepsilon_{j}}{\varepsilon_{j}-1}} \geq Y_{j, t}
$$

It is straightforward to show that the demand function for intermediate good $i$ in sector $j$ is

$$
Y_{j, t}(i)=\left(\frac{P_{j, t}(i)}{P_{j, t}}\right)^{-\varepsilon_{j}} Y_{j, t}
$$

where $P_{j, t}=\left(\int_{0}^{1} P_{j, t}(i)^{1-\varepsilon_{j}} d i\right)^{\frac{1}{1-\varepsilon_{j}}}$ is the price of final good $j$.

\subsection{Intermediate Goods Producers}

In both of the non-durable and durable goods sectors, there is a continuum of monopolistically competitive intermediate goods producers indexed by $i \in[0,1]$. Each intermediate goods producer faces the demand curve Eq. (11) for its product. It uses only labor to produce output according to the following technology

$$
Y_{j, t}(i)=A_{j, t} N_{j, t}(i),
$$

where $A_{j, t}$ is the technology in sector $j$ and $N_{j, t}(i)$ is the labor hired by firm $i$ in sector $j$.

Intermediate goods producers set nominal prices on a staggered basis. Following Calvo (1983), firms are assumed to adjust their prices infrequently with the opportunity to adjust arriving following an exogenous Poisson process. Each period, there is a constant probability $\left(1-\omega_{j}\right)$ that the firm can re-optimize its price, the $\omega_{j}$ remaining fraction update prices by a steady-state inflation rate $\pi$.

When a firm gets a chance to re-optimize its price, it sets the price $P_{j, t}^{*}$ to maximize the 
following expected discounted profit

$$
E_{t} \sum_{i=0}^{\infty} \omega_{j}^{i} \Delta_{t, t+i}\left(\frac{\left(1+\tau_{j}\right) \pi^{i} P_{j, t}^{*}}{P_{j, t+i}} Y_{j, t+i}-M C_{j, t+i} Y_{j, t+i}\right)
$$

where $M C_{j, t}=W_{t} /\left(A_{j, t} P_{j, t}\right)$ is the real marginal cost, and $\Delta_{t, t+i}=\Pi_{s=t}^{t+i} \Delta_{s}$ is the stochastic discount factor. Recall that $\Delta_{s}$ was defined in household's decision problem. The firm's output is subsidized at a fixed rate $\tau_{j}$. When a firm gets a chance to re-optimize its price in period $t$, it has to take into account that it may not get the next opportunity to re-optimize its price until period $t+i$ with a probability $\omega_{j}^{i}$. The term in brackets denotes the firm's profit (in real terms) in period $t+i$ if it does not get a chance to re-optimize its price. Note that each firm adjusting its price in period $t$ faces the same profit maximization problem in Eq. (13), so all firms will set the same price $P_{j, t}^{*}$.

Using the definition of $\Delta_{s}$ and the demand curve in Eq. (11), it is straightforward to derive $P_{j, t}^{*}$ from the maximization of Eq. (13)

$$
P_{j, t}^{*}=\left(\frac{1}{1+\tau_{j}}\right)\left(\frac{\varepsilon_{j}}{\varepsilon_{j}-1}\right) \frac{E_{t} \sum_{i=0}^{\infty} \omega_{j}^{i} \beta^{i}\left(\pi^{i}\right)^{-\varepsilon_{j}} \lambda_{t+i} M C_{j, t+i} Y_{j, t+i} P_{j, t+i}^{\varepsilon_{j}}}{E_{t} \sum_{i=0}^{\infty} \omega_{j}^{i} \beta^{i}\left(\pi^{i}\right)^{1-\varepsilon_{j}} \lambda_{t+i} Y_{j, t+i} P_{j, t+i}^{\varepsilon_{j}-1}}
$$

Following Rotemberg and Woodford (1997), set $\tau_{j}=1 /\left(\varepsilon_{j}-1\right)$ to offset the inefficiency of steady-state output due to the markup pricing of monopolistically competitive producers.

Sector $j$ 's price index satisfies the recursion

$$
P_{j, t}=\left[\left(1-\omega_{j}\right)\left(P_{j, t}^{*}\right)^{1-\varepsilon_{j}}+\omega_{j}\left(P_{j, t-1} \pi\right)^{1-\varepsilon_{j}}\right]^{\frac{1}{1-\varepsilon_{j}}} .
$$

The sectoral inflation rate is $\pi_{j, t}=P_{j, t} / P_{j, t-1}$.

The price index for the final consumption goods, $X_{t}$, satisfies

$$
P_{t}=\left[(1-\alpha) P_{c, t}^{1-\eta}+\alpha P_{d, t}^{1-\eta}\right]^{\frac{1}{1-\eta}}
$$


Table 1: The implications of various realizations of news shock (only lists situations when agents expect a rise in TFP).

Different combinations of shocks

\begin{tabular}{ccl}
\hline$\varepsilon_{j, t-p}>0$ & $\zeta_{j, t}=0$ & High expectation fully realized \\
$\mathrm{o} \varepsilon_{j, t-p}>0$ & $-\varepsilon_{j, t-p}<\zeta_{j, t}<0$ & High expectation partially realized \\
$\varepsilon_{j, t-p}>0$ & $\zeta_{j, t}=-\varepsilon_{j, t-p}$ & High expectation not realized at all \\
$\varepsilon_{j, t-p}>0$ & $\zeta_{j, t}<-\varepsilon_{j, t-p}$ & Expect a rise in TFP, actually TFP drops \\
$\varepsilon_{j, t-p}>0$ & $\zeta_{j, t}>0$ & TFP rises more than expected \\
\hline
\end{tabular}

The aggregate inflation is $\pi_{t}=P_{t} / P_{t-1}$.

\subsection{News Shocks}

As in Beaudry and Portier (2004) and Christiano et al. (2008), productivity in sector $j$ follows an autoregressive process,

$$
\ln \left(A_{j, t}\right)=\rho_{j} \ln \left(A_{j, t-1}\right)+\varepsilon_{j, t-p}+\zeta_{j, t}, \quad-1<\rho_{j}<1 .
$$

$\varepsilon_{j, t} \sim N\left(0, \sigma_{\varepsilon}^{2}\right)$ is the news shock: At date $t-p$, agents receive a signal, given by $\varepsilon_{j, t-p}$, of

a change in productivity in that sector $p$ periods hence. $\zeta_{j, t} \sim N\left(0, \sigma_{\zeta}^{2}\right)$ is a conventional productivity shock, exerting a contemporaneous effect on sector $j$ productivity.

Suppose that $\varepsilon_{j, t-p}>0$. Between dates $t-p$ and $t$, agents will expect an improvement in sector $j$ productivity. At date $t$, the shock $\zeta_{j t}$ is realized. There are a number of possibilities, summarized in Table 1. If $\zeta_{j t}=0$, then the news shock is perfectly informative of the change in productivity at $t$. When $\zeta_{j t}>0$, sector $j$ productivity is higher than expected. The productivity shock could exactly offset the news shock if $\zeta_{j t}=-\varepsilon_{j, t-p}$; it partially offsets the news shock if $\zeta_{j t}<-\varepsilon_{j, t-p}$. Finally, should it be the case that $\zeta_{j t}>-\varepsilon_{j, t-p}$, then the productivity shock overwhelms the news shock and productivity actually falls. 


\subsection{Monetary Policy}

The final actor in the economy is the central bank. Two different behavioral assumptions are made. First, an exogenous money supply rule; and second, a Ramsey optimal monetary policy.

The government budget constraint is

$$
B_{t}+M_{t}=R_{t-1} B_{t-1}+M_{t-1}+T_{t}+\int_{0}^{1} \tau_{c} P_{c t}(i) Y_{c t}(i) d i+\int_{0}^{1} \tau_{d} P_{d t}(i) Y_{d t}(i) d i
$$

\subsubsection{Exogenous Monetary Supply Rule}

To highlight the effects of different monetary policies on the responses to news about the future technology change, an exogenous monetary supply rule is added to the model as a baseline case. Money is injected into the economy through lump sum transfer $T_{t}$.

The gross growth rate of money evolves according to

$$
g_{t}=\rho_{g} g+\left(1-\rho_{g}\right) g_{t-1}+\xi_{t}, \quad \xi_{t} \sim N\left(0, \sigma_{\xi}^{2}\right)
$$

where $g$ is the steady-state money growth rate. By definition, $M_{t}=g_{t} M_{t-1}$. The money supply shock, $\xi_{t}$, is assumed to be independent of the news and productivity shocks.

\subsubsection{Ramsey Optimal Monetary Policy}

Alternatively, suppose that the central bank solves a Ramsey problem. ${ }^{4}$

The central bank's problem is

$$
\max E_{0} \sum_{t=0}^{\infty} \beta^{t} U\left(X_{t}, N_{t}\right)
$$

subject to the households' first-order conditions, Eqs. (5)-(7), optimal price setting by re-

\footnotetext{
${ }^{4}$ Some recent examples of papers solving central bank Ramsey problems are the following: Levin, Onatski, Williams and Williams (2006), Khan, King and Wolman (2003), Siu (2004), and Schmitt-Grohé and Uribe (2004).
} 
optimizing intermediate goods firms, Eq. (14), and market clearing conditions, Eqs. (20)$(22) .^{5}$

Solving this problem generates the first order conditions that characterize the Ramsey optimal policy. ${ }^{6}$ These first order conditions are bundled together with the private sector's behavioral equations and the market-clearing conditions to analyze the behavior of the economy under the Ramsey optimal policy.

\subsection{Aggregation and Equilibrium}

Having described the behaviors of individual agents, we now turn to the aggregation of individual outputs. Integrating both sides of the intermediate goods production function, Eq. (12), yields

$$
\int_{0}^{1} Y_{j, t}(i) d i=\int_{0}^{1} A_{j, t} N_{j, t}(i) d i=A_{j, t} N_{j, t}
$$

where $N_{j, t}=\int_{0}^{1} N_{j, t}(i) d i$.

Using the demand function, Eq. (11), Eq. (18) can be rewritten as:

$$
\underbrace{\left[\int_{0}^{1}\left(\frac{P_{j, t}(i)}{P_{j, t}}\right)^{-\varepsilon_{j}} d i\right]}_{s_{j t}} Y_{j, t}=A_{j, t} N_{j, t}
$$

where $s_{j, t}$ captures the resource costs due to inefficient price dispersion that is caused by the Calvo-type staggered price adjustment: At time $t$, only the fraction $\left(1-\omega_{j}\right)$ of intermediate goods producers have the opportunity to re-optimize their prices to $P_{j, t}^{*}$; the fraction $(1-$ $\left.\omega_{j}\right) \omega_{j}$ last had the opportunity to re-optimize at time $t-1$; likewise, $\left(1-\omega_{j}\right) \omega_{j}^{i}$ is the fraction of intermediate goods firms who last re-optimized their prices $i$ periods ago - the charge a price $P_{j, t-i}^{*} \pi^{i}$. This price dispersion can be written recursively as

$$
s_{j, t}=\int_{0}^{1}\left(\frac{P_{j, t}(i)}{P_{j, t}}\right)^{-\varepsilon_{j}} d i
$$

\footnotetext{
${ }^{5}$ Refer to Appendix B for the Ramsey problem in detail.

${ }^{6}$ See Appendix $\mathrm{C}$ for the first order conditions of the Ramsey problem.
} 


$$
\begin{aligned}
& =\left(1-\omega_{j}\right)\left(\frac{P_{j, t}^{*}}{P_{j, t}}\right)^{-\varepsilon_{j}}+\left(1-\omega_{j}\right) \omega_{j}\left(\frac{P_{j, t-1}^{*} \pi}{P_{j, t}}\right)^{-\varepsilon_{j}}+\left(1-\omega_{j}\right) \omega_{j}^{2}\left(\frac{P_{j, t-2}^{*} \pi^{2}}{P_{j, t}}\right)^{-\varepsilon_{j}}+\ldots \\
& =\left(1-\omega_{j}\right)\left(\frac{P_{j, t}^{*}}{P_{j, t}}\right)^{-\varepsilon_{j}}+\omega_{j}\left[\left(1-\omega_{j}\right)\left(\frac{P_{j, t-1}^{*} \pi}{P_{j, t-1} \pi_{j, t}}\right)^{-\varepsilon_{j}}+\left(1-\omega_{j}\right) \omega_{j}\left(\frac{P_{j, t-2}^{*} \pi^{2}}{P_{j, t-1} \pi_{j, t}}\right)^{-\varepsilon_{j}}+\ldots\right] \\
& =\left(1-\omega_{j}\right)\left(\frac{\hat{P}_{j, t}^{*}}{\hat{P}_{j, t}}\right)^{-\varepsilon_{j}}+\omega_{j}\left(\frac{\pi}{\pi_{j, t}}\right)^{-\varepsilon_{j}} s_{j, t-1}
\end{aligned}
$$

where $\hat{P}_{j, t}^{*}=P_{j, t}^{*} / P_{t}$, and $\hat{P}_{j, t}=P_{j, t} / P_{t}$.

The definition of an equilibrium is fairly standard and is omitted for the sake of brevity. The remaining market clearing conditions are:

$$
\begin{aligned}
\text { Non-durables: } & Y_{c, t}=C_{t} \\
\text { Durables: } & Y_{d, t}=D_{t}-(1-\delta) D_{t-1} \\
\text { Labor: } & N_{t}=N_{c, t}+N_{d, t}
\end{aligned}
$$

Appendix A summarizes the equations describing the model equilibrium, where all the nominal variables have been transformed to induce stationarity.

\section{Calibration and Solution}

The model is calibrated to a quarterly frequency. Some parameter values are standard in the business cycle literature. The discount factor $\beta$ is set to be 0.99 , consistent with a steady state annualized real interest rate of about 4\%. Based on evidence presented in Gomme and Rupert (2007), the quarterly depreciation rate of the durable stock $\delta$ is set to 0.058, implying an annual depreciation rate of $21.3 \%$. $\alpha$, the parameter in the composite consumption index $X_{t}$, is chosen so that the steady state share of durable goods output in total output is 0.25 . The parameter $\sigma$ is set to be 1 so that the elasticity of labor supply is unity. The parameter $v$ in the utility function is set so that steady-state labor supply is $1 / 3$. The autoregressive coefficient in the productivity process $\rho_{j}$ is set to 0.95 . The total 
innovation to sector $j$ productivity is the sum of its news and productivity shocks. Since these shocks are assumed to be independent, the standard deviation of the total innovation is $\sqrt{\sigma_{\varepsilon}^{2}+\sigma_{\zeta}^{2}}$. Prescott (1986) finds that the standard deviation of the total innovation is 0.00763. We attribute half of this standard deviation to each of the news and productivity shocks. Thus, $\sigma_{\varepsilon}=\sigma_{\zeta}=0.00763 / \sqrt{2}=0.0054$.

Following Beaudry and Portier (2004), the elasticity of substitution between non-durable goods and durable goods, $\eta$, is set to be 0.2 in the baseline case, implying a strong complementarity between the non-durable goods and durable goods.

The parameter $\omega_{j}$ determines how long a price contract will last. ${ }^{7}$ The empirical evidence surveyed by Taylor (1999) suggests that nominal price contracts on average last for a year, implying $\omega_{j}=0.75$. Bils and Klenow (2004) argue that the observed frequency of price adjustment in the U.S. is much higher, or in the order of two quarters, implying $\omega_{j}=0.5$. In the recent literature considering two-sector models with nominal rigidities, Erceg and Levin (2006) assume symmetric price rigidities in non-durable and durable sectors. Barsky et al. (2007) and Monacelli (2009) study the cases with asymmetric price rigidities. They argue that the prices of durable goods adjust more frequently than non-durable goods in that the menu cost relative to the unit price of durable goods is much lower. We set $\omega_{j}=0.75$ for both sectors in the baseline calibration, but allow for asymmetric price rigidities in the approximation of the Ramsey policy.

The parameters $\varepsilon_{j}(j \in\{c, d\})$ measure the elasticity of substitution between differentiated intermediate goods. Following Monacelli (2009), we set both parameters to 8, which yields a steady state mark-up of $15 \%$ for intermediate goods producers.

The values of all the baseline parameters are summarized in Table 2 .

The model is solved by taking a log-linear approximation of the equilibrium conditions in the neighborhood of the steady state.

\footnotetext{
${ }^{7}$ The expected time between price adjustments is $1 /\left(1-\omega_{j}\right)$.
} 
Table 2: Baseline Parameter Values.

\begin{tabular}{cccccccccccccc}
\hline$\beta$ & $\alpha$ & $\delta$ & $\eta$ & $\sigma$ & $v$ & $\varepsilon_{c}$ & $\varepsilon_{d}$ & $\omega_{c}$ & $\omega_{d}$ & $\rho_{c}$ & $\rho_{d}$ & $\sigma_{\varepsilon}$ & $\sigma_{\zeta}$ \\
\hline 0.99 & 0.87 & 0.058 & 0.2 & 1 & 0.91 & 8 & 8 & 0.75 & 0.75 & 0.95 & 0.95 & 0.0054 & 0.0054 \\
\hline
\end{tabular}

\section{Simulation Results}

In this section, responses to news about future technology improvement are explored in three cases: an exogenous money supply rule; a Ramsey optimal policy; and flexible prices. Through the comparison of the responses in these three cases, we can highlight the effects of adding nominal rigidities and different monetary policies on the responses to a news shock. In each of the three cases, we focus on the co-movements of the non-durable goods and durable goods sectors. The key issue is whether the model can generate a boom of production in both sectors after agents receive news about the future technology improvement.

In period 1 , agents receive a $1 \%$ sector-j news shock meaning that they expect sector-j total factor productivity, $A_{j}$, to be higher in period 5 . During periods 1 to 4 , agents will act on that expectation. In period 5 , the realization of $\ln \left(A_{j, 5}\right)$ is determined by the realization of $\zeta_{j, 5}$. If it happens that $\zeta_{j, 5}=-\varepsilon_{j, 1}$, then the expected positive move in $\ln \left(A_{j, 5}\right)$ does not occur. Following Beaudry and Portier (2004), we first assume that agents receive a signal suggesting that the technology will increase in the non-durable sector. The results of this experiment are summarized in Figure 1.

\subsection{Exogenous Money Supply}

\subsubsection{Flexible Prices}

When households receive the signal about the future technology improvement in the nondurable sector, they want more durables as well owing to the complementarity between non-durable and durable goods. Households start to accumulate durable goods immediately after they receive the signal about the future technology improvement in non-durable sector, 
which boosts the production of durable goods and labor allocated to that sector. However, the response of total labor is quite modest owing to a decline in non-durable good production, and so labor in that sector. With flexible prices, the relative price remains unchanged since prices in both sectors are a constant markup over the marginal cost, which is the ratio of the wage to the marginal product. With a linear production technology, the marginal product of labor is simply the technology level, and the wage is equalized across the two sectors. As long as the technology does not change, the relative price will remain unchanged.

In a similar two sector model without any nominal rigidities, Beaudry and Portier (2004) succeed in generating positive comovements between non-durable and durable goods, and an increase of the relative price after agents receive news about a future technology improvement. Two differences between their model and the one presented in this paper can explain the discrepancy. First, Beaudry and Portier assume a decreasing marginal product of labor while we assumed a constant one. With a decreasing marginal product of labor, the marginal cost in the durable sector increases when labor employed in that sector rises, which causes an increase in the relative price. The increase in the price of durable goods relative to nondurable goods dampens the incentive to accumulate durable goods and boosts the demand of non-durable goods, both of which help generate the positive comovements. Second, as pointed out in Beaudry and Portier, the infinite elasticity of labor supply (indivisible labor) assumed in their model also helps generate the positive comovements.

\subsubsection{Nominal Price Rigidities}

Under an exogenous money supply rule, output in both sectors, and so labor, experience a boom after agents receive the non-durable sector news shock, and the relative price of durables rises. The economy experiences a bust when this news shock is offset by the contemporaneous technology shock. Since the only difference between the previous economy and the current one is nominal price rigidities, it is clear that these rigidities are responsible for the rise in the relative price of durables, and the positive comovement across the two 
Figure 1: Responses to an Unrealized News Shock in the Non-durable Good Sector

(a) Non-durable Goods, $c$

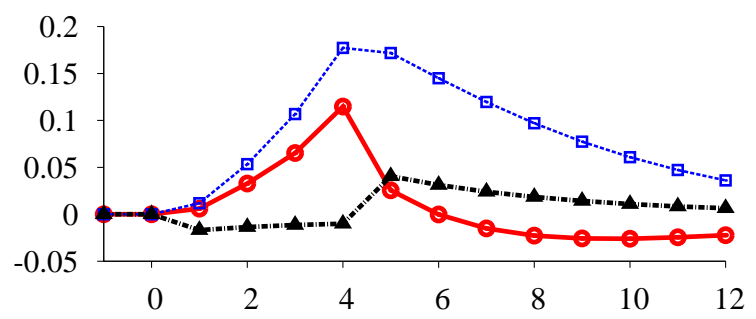

(c) Durables Production, $i$

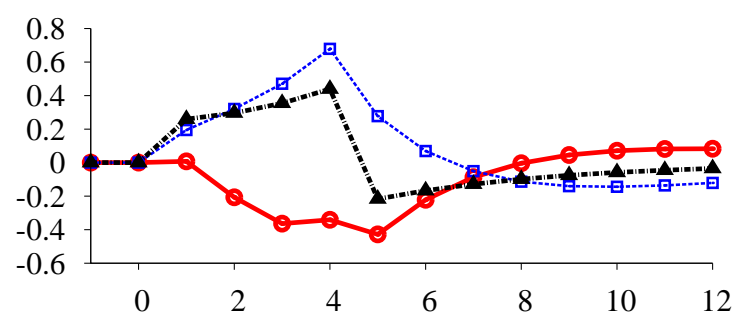

(e) Relative Price

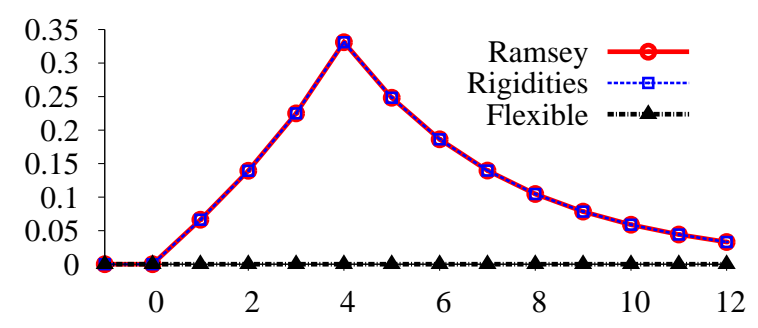

(g) Durables Sector Inflation

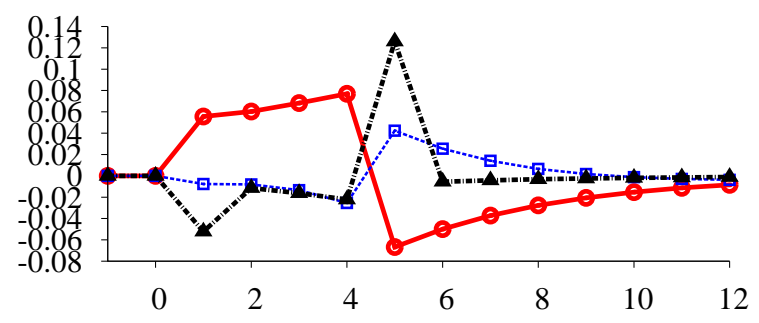

(i) Real Interest Rate, Durables

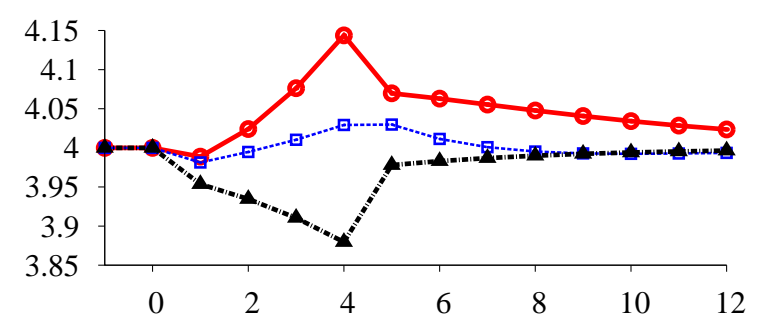

(b) Stock of Durables, $d$

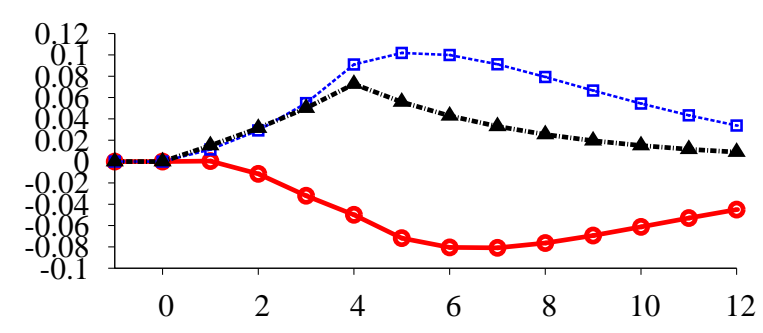

(d) Labor Supply

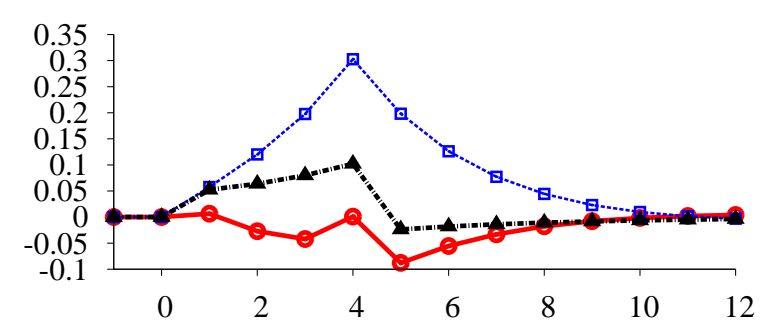

(f) Nominal Interest Rate

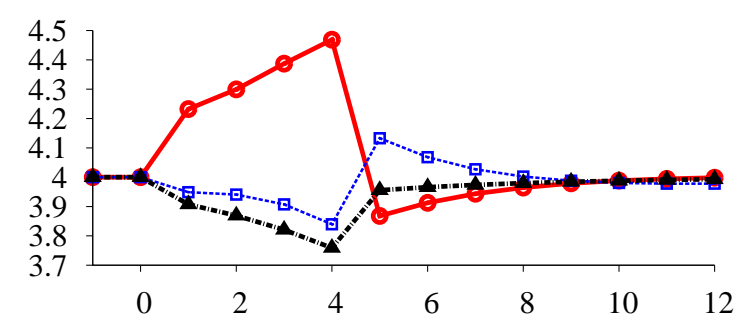

(h) Non-durable Sector Inflation

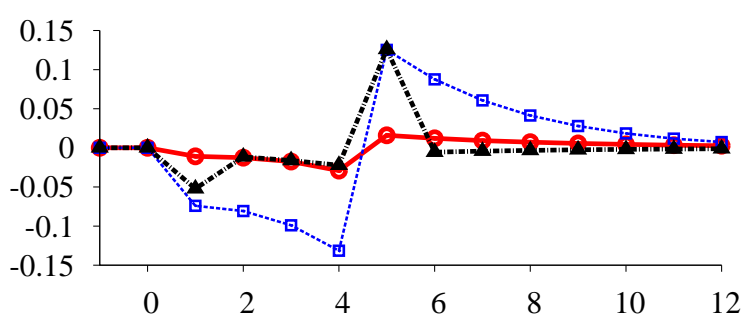

(j) User Cost

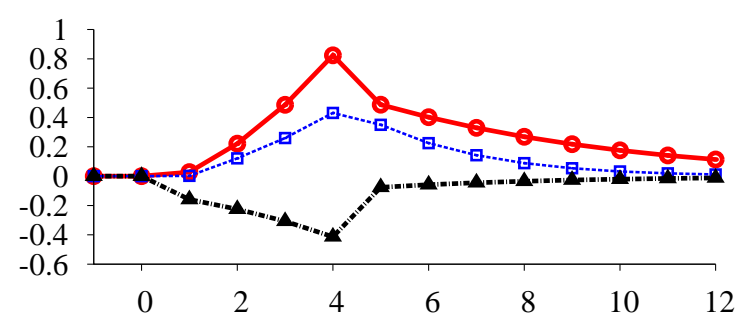


sectors. The underlying mechanism is as follows: When prices are sticky, producers decide their prices based on the weighted average of the current and future marginal costs. Nondurable goods producers expect that marginal costs will drop in the future due to technology improvements, and start to lower their prices in advance of the actual change in total factor productivity since they are uncertain when they will be able to change their prices. Consequently, the relative price of durables rises. The fall in the price of non-durables leads households to increase their consumption of these goods. Owing to the complementarity between durables and non-durables, they also increase their consumption of durables. As pointed out in Barsky et al. (2007), one of the features of two sector models with long-lived durable goods is that the demand for non-durable goods is determined by the relative price. The co-movement between non-durable goods production and the relative price in Figure 1 is consistent with their conclusion. In sum, the introduction of nominal rigidities results in a rise in the relative price of durables, and ultimately a boom in both sectors - non-durables because of the lower price of these goods, durables because of the complementarity with non-durables.

\subsection{Responses Under the Ramsey Optimal Policy}

To highlight the effect of the Ramsey optimal monetary policy on the responses, we focus on comparing the responses under an exogenous money supply with nominal price rigidities, and those under the Ramsey policy. First, under the Ramsey policy, the news about a rise in the non-durable sector technology only generates a boom in the non-durable sector. Meanwhile, the durable goods sector experiences a moderate bust. There is almost no response in the total labor supply: The behavior of the relative price is virtually identical between the Ramsey policy and the exogenous money supply rule. ${ }^{8}$ Consequently, the response of nondurable goods is similar to that under an exogenous money supply. The mechanism driving the bust in the durable sector is as follows. The Ramsey policy prescribes an increase in the

\footnotetext{
${ }^{8}$ This is true only when the degrees of nominal rigidities are assumed to be the same in two sectors. When asymmetric nominal rigidities are assumed, monetary policy has some effect on the relative price.
} 
nominal interest rate whereas the exogenous money supply rule has a decrease. As a result, the real interest rate in the durable good sector, and so the user cost of durables, rises under the Ramsey policy. Household purchases of durable goods are determined by two forces: the complementarity between non-durable and durable goods pushes their quantity up, while the rise of the user cost pushes their quantity down. The net effect of these two forces is that durable goods decline by a moderate amount.

Comparing responses under the Ramsey policy with those under flexible prices, we can observe that the Ramsey policy does not lead the economy to behave as under flexible prices. The Ramsey policy involves a trade off that cannot fully remove the distortion caused by the nominal rigidities. First, consumption of non-durable goods is determined chiefly by the relative price. Since monetary policy has no impact on the relative price when the nominal rigidities are the same in the two sectors, it has no impact on the consumption of non-durable goods. Regardless of the monetary policy rule applied, the relative price of durable goods and the consumption of non-durable goods will increase when agents expect an improvement in technology in the non-durable sector. Suppose that the Ramsey policy tried to restore the combination of non-durable goods and durable goods, $X_{t}$, to its flexible price level; then durable goods production must fall sharply in order to have a sufficient impact on the stock of durables. But such a large decline in durable production will push total labor supply far below its flexible price level. Second, if the Ramsey policy tries to restore total labor supply to its flexible price level, labor has to move from the durable goods sector to the non-durable goods sector, which lowers output of durable goods. However, the stock of durable goods is almost unchanged since the investment flow into durables is small relative to its stock. In this case, the Ramsey policy fails to restore the combination of non-durable goods and durable goods, $X_{t}$, to flexible price level. In sum, the Ramsey policy can not restore both the combination of non-durable goods and durable goods, $X_{t}$, and the total labor supply to their flexible price levels. It turns out that in evaluating these trade offs, the Ramsey policy ends up with a total quantity of labor close to its flexible price level. The Ramsey policy 
implies an increase in the nominal interest rate so that the real interest rate and user cost of durable goods increase. This increase in the real interest rate reduces the incentive to accumulate durable goods. The muted response of durable goods production allows more labor to be allocated to the non-durable goods sector. It is also interesting to note that the Ramsey optimal policy fails to stabilize the inflations in both sectors due to the variations in the relative price. For if the relative price fluctuates while the inflation in one sector remains constant, there must be a variable inflation rate in another sector.

\subsection{Model Features That Help Generating the Boom and Bust}

The previous experiments show that we succeed in generating a boom in both sectors in the model with nominal rigidities and an exogenous money supply, but fails to do so in the model with flexible prices or in the model with nominal rigidities and the Ramsey policy. These

results indicate that both nominal rigidities and monetary policy play significant roles in generating Pigou cycles. Beaudry and Portier (2004) attributes their success in generating Pigou cycles to the following features of their model: (1) the complementarity between non-durable goods and durable goods; and (2) an expectation of technology improvement in non-durable sector instead of durable sector. To see whether these features are still indispensable in generating Pigou cycles in our framework, we change these features of the model to alternative ones and compare the differences of impulse responses under alternative assumptions.

First, we change the elasticity of substitution between non-durable goods and durable goods, $\eta$, from 0.2 to 2 leaving the other parameters in the model unchanged. In this case, non-durables and durables are good substitutes. The impulse responses in Figure 2 show that the model fails to generate a boom in the durable goods sector when agents expect an productivity improvement in the non-durable sector in all three model variants. An expected productivity improvement in the non-durable sector leads to a lower price of non-durable goods relative to that of durable goods. Therefore, households will reduce the demand 
for durable goods since they can be easily replaced by the non-durable goods that are less expensive. This experiment verifies that complementarity between non-durable goods and durable goods still plays a significant role in generating Pigou cycles in a two-sector model.

Next, we assume that agents receive a signal suggesting a technology rise in the durable sector instead of non-durable sector. The impulse responses in Figure 3 are also consistent with Beaudry and Portier's result: macro aggregates move downwards together when agents expect a rise of technology in durable sector. Since agents expect a technology improvement in the durable sector and so a drop in the relative price of durable goods, they postpone their investment in durable sector until the realization of the technology improvement. This observation verifies that the assumption that agents receive signals about improvements in the non-durable sector is essential to generate Pigou cycles.

\section{Approximating the Ramsey Policy With Simple Pol- icy Rules}

\subsection{Baseline parameters}

Following Taylor (1993), numerous researchers have estimated or evaluated a multitude of simple monetary policy rules. The policies are simple in the sense that they involve only a few observable macroeconomic variables. Since these simple rules only react to a small number of observed variables, they are inferior to Ramsey policy which, by definition, maximize lifetime utility of the representative agent, subject to the constraints faced by the planner. The virtue of simple rules is that they are easier to explain to the public, lending an air of transparency to monetary policy. The question asked here is whether a relatively simple interest rate rule comes close to replicating the behavior of the economy under the Ramsey policy. Armed with artificial time series from the model solved under the Ramsey rule, we 
Figure 2: Responses to an Unrealized News Shock: Higher Elasticity of Substitution between Durables and Non-durables

(a) Non-durable Goods, $c$

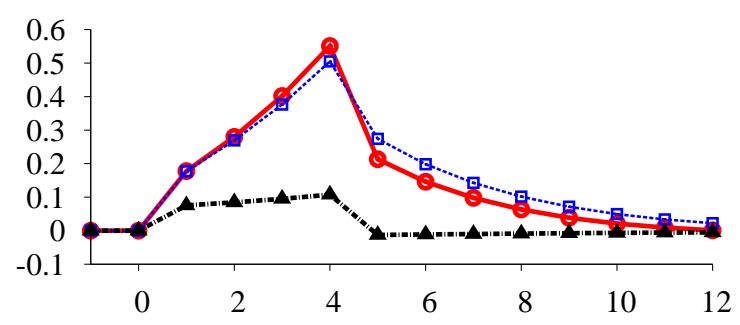

(c) Durables Production, $i$

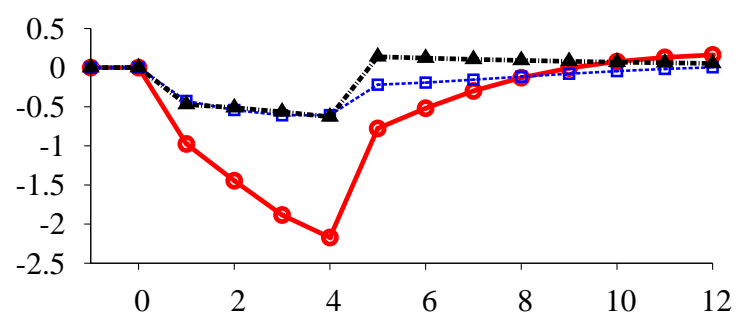

(e) Relative Price

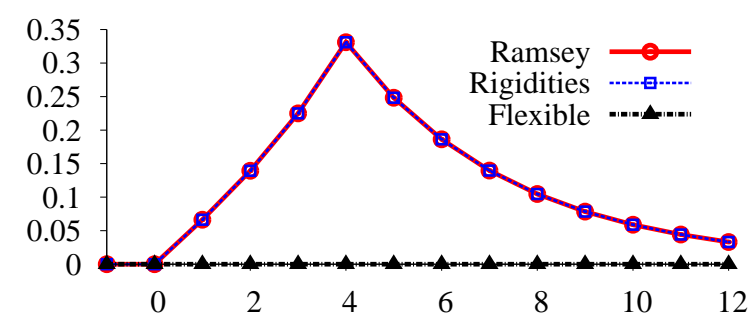

(g) Durables Sector Inflation

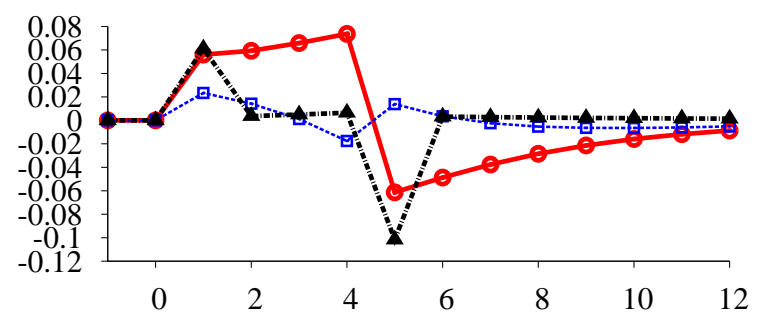

(i) Real Interest Rate, Durables

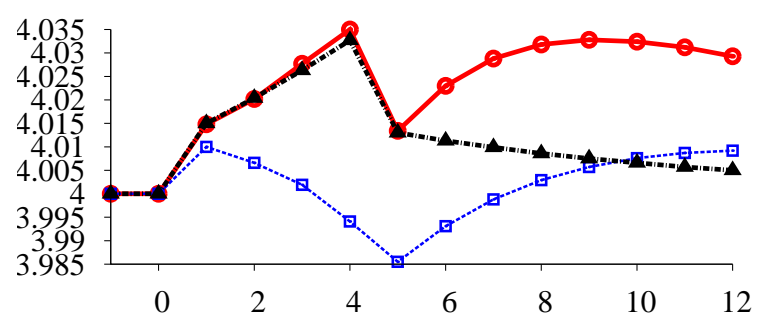

(b) Stock of Durables, $d$

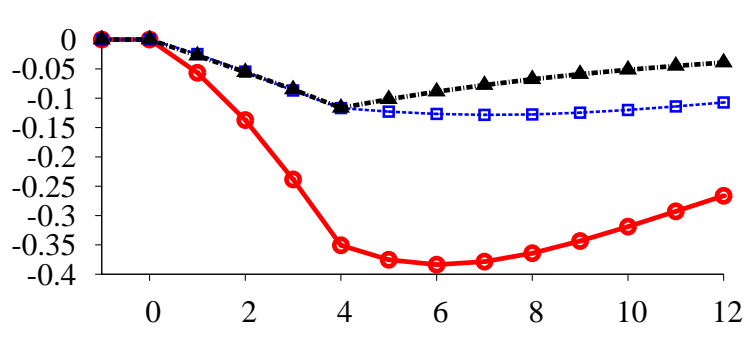

(d) Labor Supply

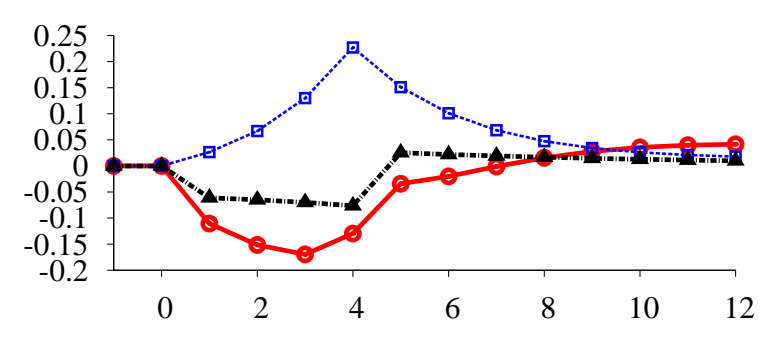

(f) Nominal Interest Rate

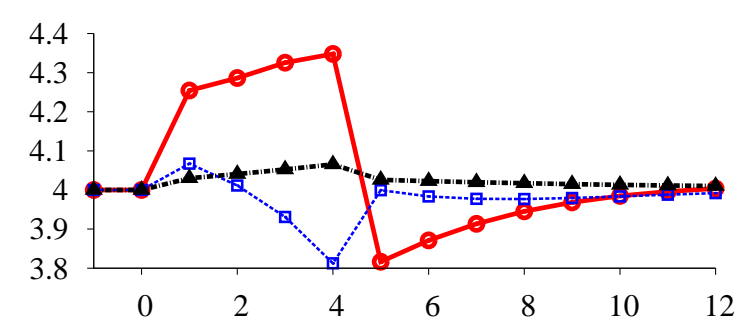

(h) Non-durable Sector Inflation

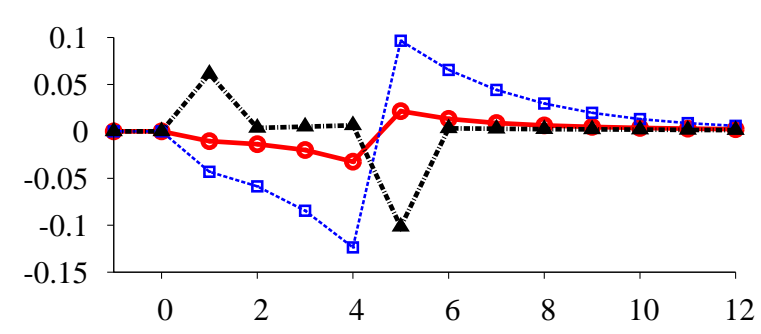

(j) User Cost

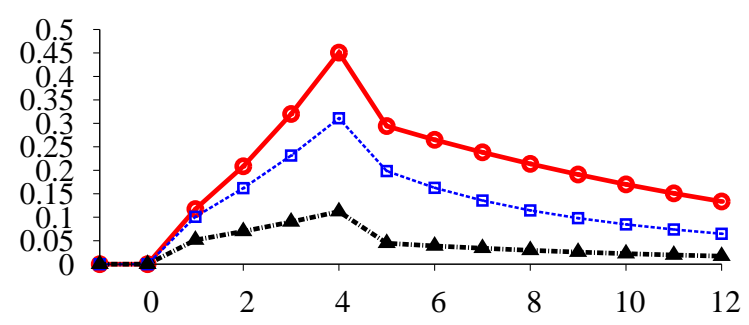


Figure 3: Responses to an Unrealized News Shock to the Durable Sector

(a) Non-durable Goods, $c$

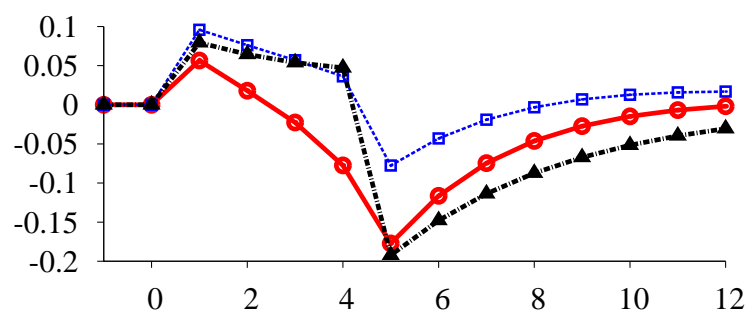

(c) Durables Production, $i$

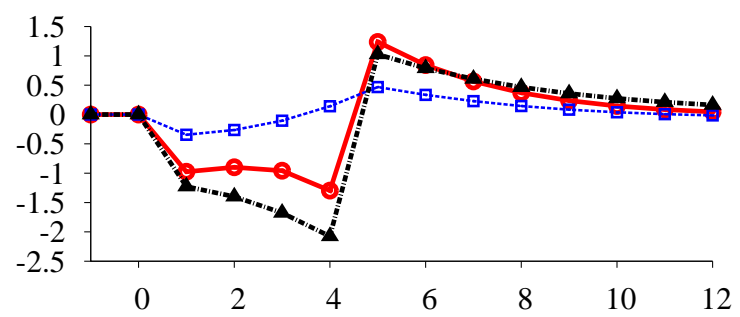

(e) Relative Price

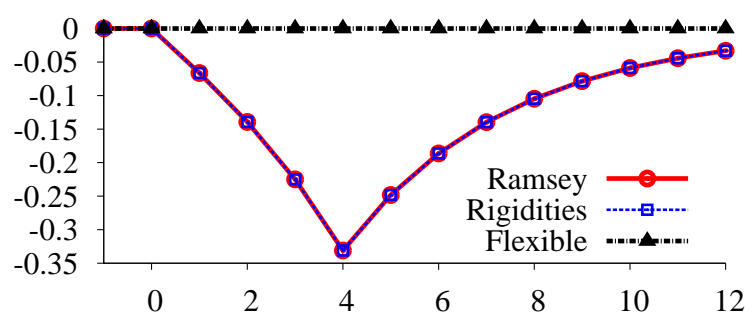

(g) Durables Sector Inflation

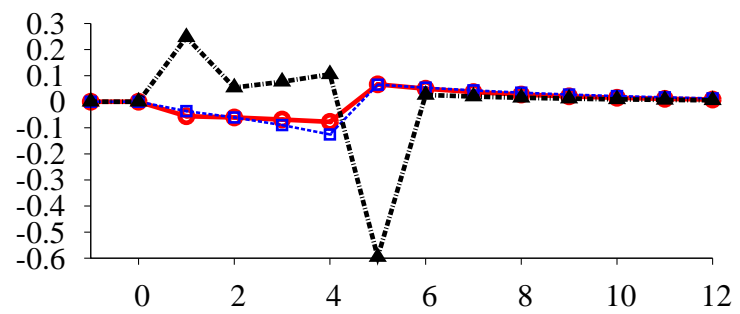

(i) Real Interest Rate, Durables

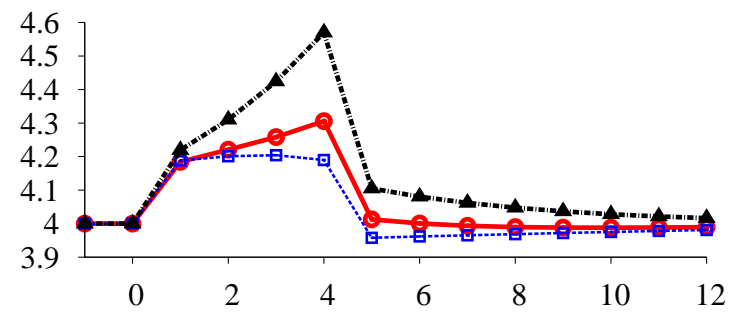

(b) Stock of Durables, $d$

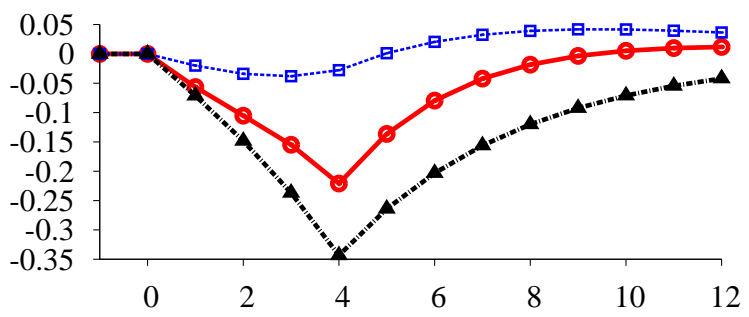

(d) Labor Supply

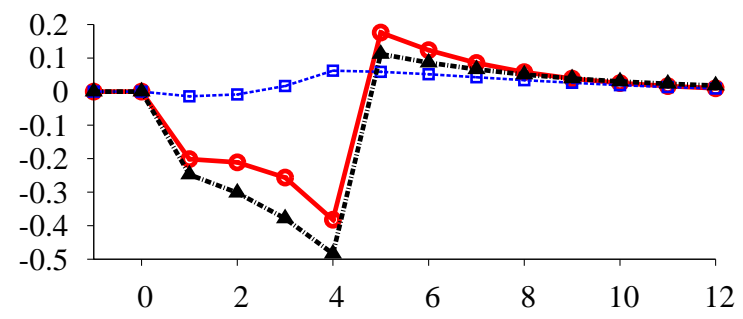

(f) Nominal Interest Rate

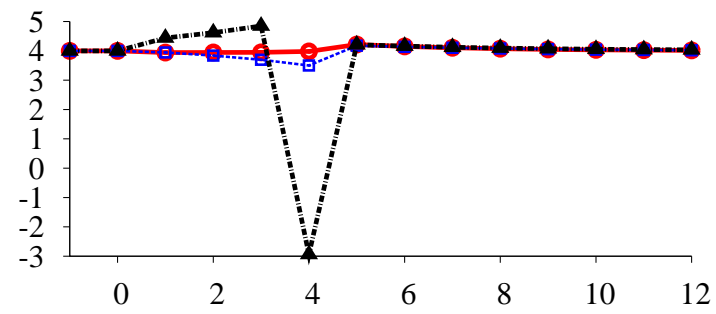

(h) Non-durable Sector Inflation

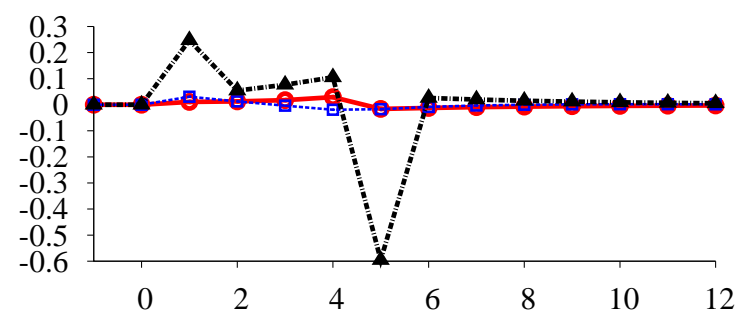

(j) User Cost

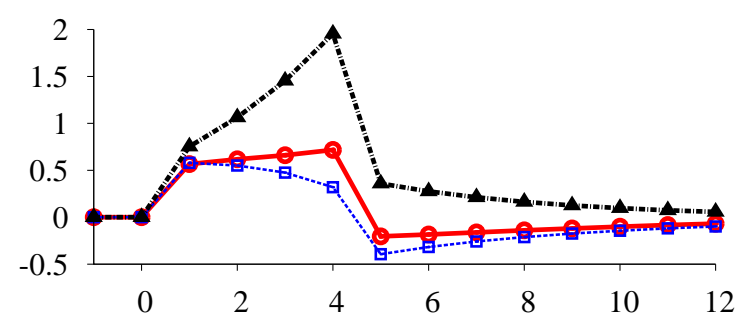


estimate the following equations: ${ }^{9}$

$$
\begin{aligned}
& R_{t}=\alpha_{0}+\alpha_{1} \pi_{t}+\alpha_{2} x_{t}+e_{t} \\
& R_{t}=\beta_{0}+\beta_{1} \pi_{c, t}+\beta_{2} \pi_{d, t}+\beta_{3} y_{c, t}+\beta_{4} y_{d, t}+u_{t} .
\end{aligned}
$$

In Eq. (23), $R_{t}$ is the annualized nominal interest rate, $\pi_{t}$ is the aggregate inflation rate and $x_{t}$ is the output gap measured as the percentage deviation of the final consumption good, $X_{t}$, from its steady state. In Eq. (24), $\pi_{c, t}$ and $\pi_{d, t}$ are annualized inflation rates in non-durable and durable sector respectively, while $y_{c, t}$ and $y_{d, t}$ are output gaps in the non-durable and durable sectors measured as percent deviations from their steady state values. Eq. (23) is the original Taylor rule specification. Eq. (24) gauges the additional benefit of targeting sectoral inflations and output gaps. To generate artificial time series, shocks $\varepsilon_{t}$ and $\zeta_{t}$ are drawn from the normal distribution, then time series of size 1000 for $R_{t}, \pi_{t}, x_{t}, \pi_{c, t}, \pi_{d, t}, y_{c, t}$, $y_{d, t}$ are generated using the equilibrium decision rules.

The OLS estimates of the simple rule Eq. (23) are:

$$
R_{t}=\underset{(0.0095)}{4.002}+\underset{(0.0122)}{1.407} \pi_{t}-\underset{(0.0034)}{0.084} x_{t}, \quad R^{2}=0.932
$$

Those for rule Eq. (24) are:

$$
R_{t}=\underset{(0.0071)}{4.004}-\underset{(0.0592)}{1.129} \pi_{c, t}+\underset{(0.0194)}{0.834} \pi_{d, t}-\underset{(0.0035)}{0.005} y_{c, t}-\underset{(0.0026)}{0.072} y_{d, t}, \quad R^{2}=0.962
$$

Based on $R^{2}$, the two estimated rules fit the Ramsey policy-generated data quite well. Further, it seems that targeting sectoral inflation and output gaps does not substantially affect the goodness of fit. ${ }^{10}$ Interestingly, the estimates in Eq. (25) do not resemble con-

\footnotetext{
${ }^{9}$ For the purposes of estimating Taylor rules, the variances of the durable sector shocks are set to zero since it is only the non-durable sector news shocks that can potentially generate Pigou cycles. The results in this section are qualitatively similar if the durable sector shocks are in play.

${ }^{10}$ Targeting sectoral inflation and output gap will bring additional benefit when asymmetric nominal rigidity is assumed in the next subsection.
} 
Table 3: Estimation of Simple Policy Rules Under Asymmetric Nominal Rigidities

\begin{tabular}{|c|c|c|c|c|c|c|c|c|c|}
\hline \multicolumn{10}{|c|}{ Nominal Rigidity } \\
\hline$\omega_{c}$ & $\omega_{d}$ & $\beta_{1}$ & $\beta_{2}$ & $\beta_{3}$ & $\beta_{4}$ & $R^{2}$ & $\alpha_{1}$ & $\alpha_{2}$ & $R^{2}$ \\
\hline 0.75 & 0.75 & -1.129 & 0.834 & -0.005 & -0.072 & 0.962 & 1.407 & -0.084 & 0.932 \\
\hline 0.75 & 0.5 & 0.203 & 1.193 & 0.098 & -0.173 & 0.960 & 1.071 & -0.072 & 0.899 \\
\hline 0.75 & 0.4 & 1.731 & 1.265 & 0.145 & -0.223 & 0.942 & 0.981 & -0.066 & 0.865 \\
\hline 0.75 & 0.3 & 4.303 & 1.347 & 0.176 & -0.313 & 0.916 & 0.865 & -0.125 & 0.788 \\
\hline 0.75 & 0.25 & 6.880 & 1.394 & 0.253 & -0.369 & 0.897 & 0.812 & -0.121 & 0.749 \\
\hline
\end{tabular}

ventional estimates of the Taylor rule in that the coefficient on output gap is negative. The coefficient on inflation is greater than 1, which indicates that the central bank raises nominal interest rate more than the inflation rate which is necessary to ensure an increase in the real interest rate. Figure 4 shows impulse responses of selected variables under the Ramsey optimal policy and the estimated rule Eq. (25). For the most part, the time series behavior of variables are quite similar across the two policies.

\subsection{Asymmetric nominal rigidities}

The above experiments show that a simple estimated rule can approximate the Ramsey policy quite well in the case of the baseline parameters. This section explores how the interest rate reaction function changes with alternative parameters. The baseline calibration assumes symmetric nominal rigidity in the two sectors. The experiment conducted here is to allow for different degrees of nominal rigidities in the two sectors. Again, given time series from the model generated under the Ramsey rule, we estimate simple Taylor-like interest rate rules as in Eqs. (23) and (24). Apart from the degrees of nominal rigidities, all parameters are kept at their baseline values.

The estimated policy functions are summarized in Table 3. To start, notice that the estimated policy rules are a good fit to the "data." However, the fit becomes worse when the asymmetry in nominal rigidities gets larger. As this asymmetry becomes more pronounced, 
Figure 4: Responses to an Unrealized News Shock to the Non-durable Sector: Ramsey Rule versus Estimated Taylor Rule

(a) Non-durable Goods, $c$

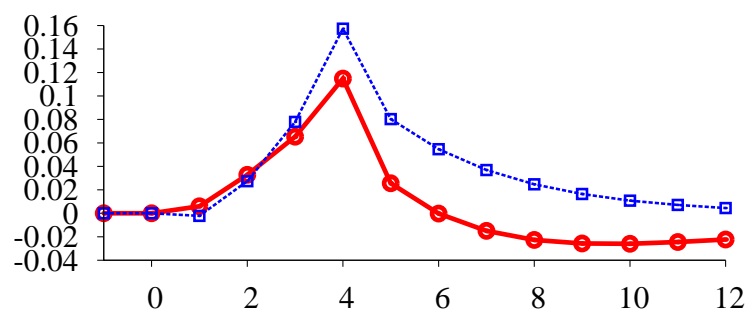

(c) Durables Production, $i$

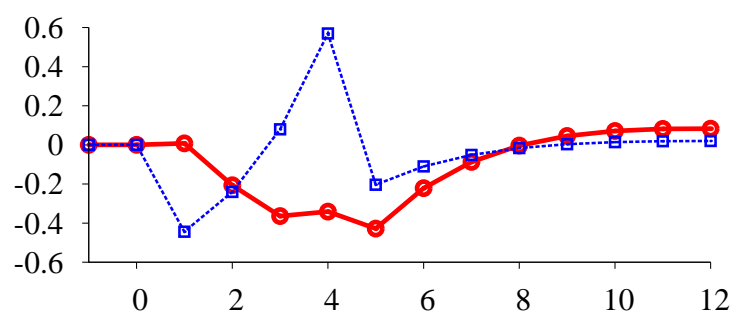

(e) Relative Price

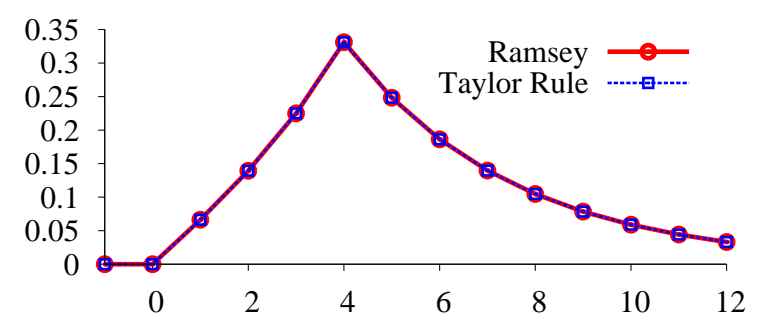

(g) Durables Sector Inflation

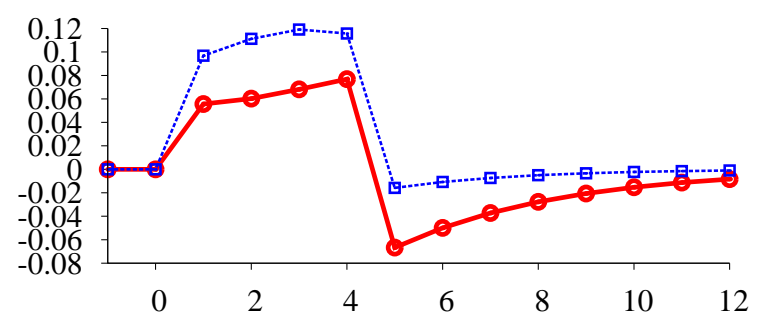

(i) Real Interest Rate, Durables

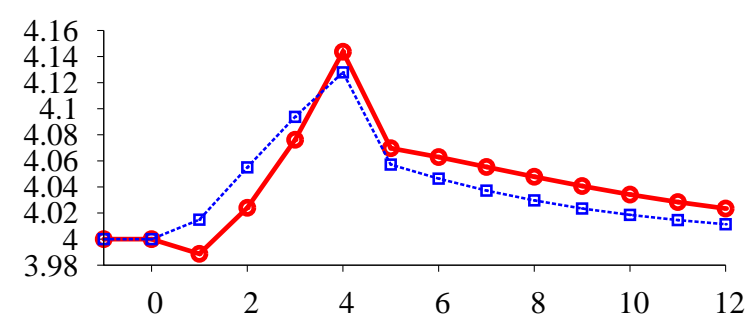

(b) Stock of Durables, $d$

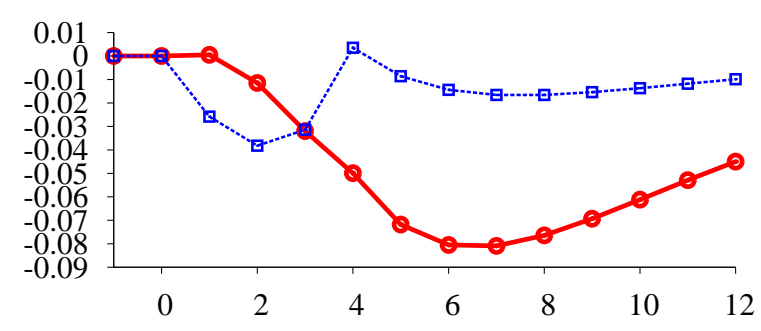

(d) Labor Supply

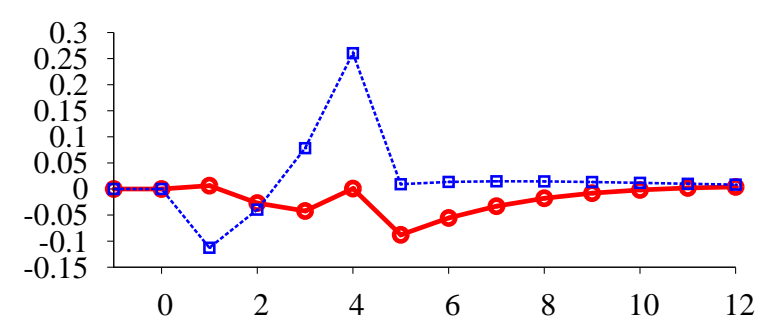

(f) Nominal Interest Rate

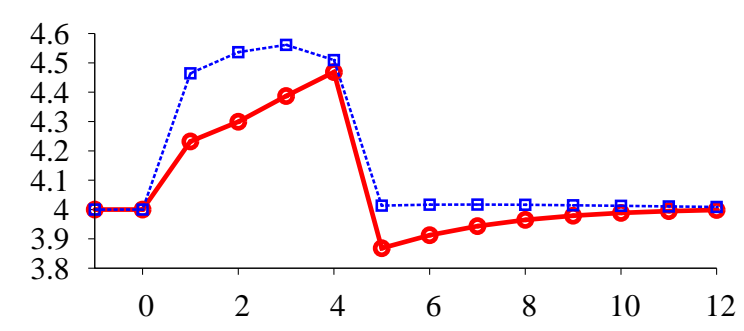

(h) Non-durable Sector Inflation

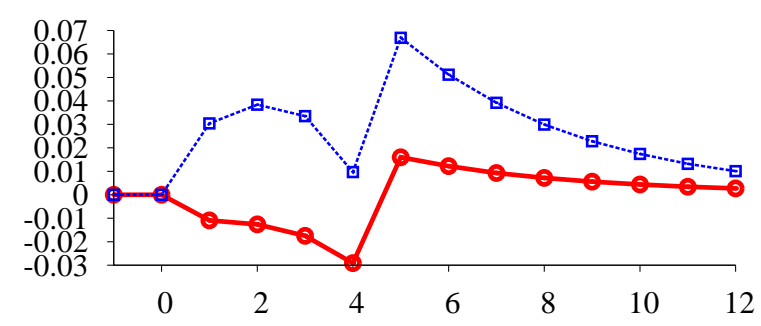

(j) User Cost

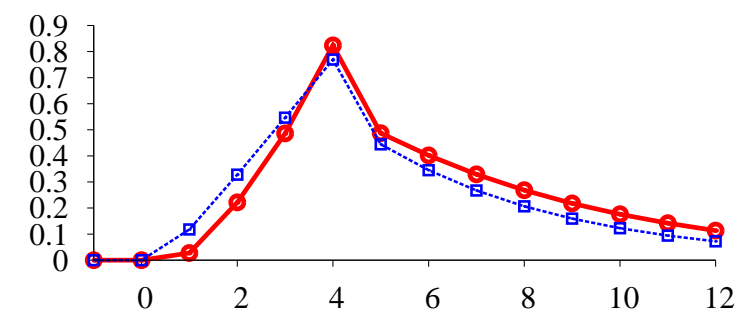


Table 4: Estimation of simple policy rules under various elasticity of substitution

\begin{tabular}{cccccc}
\hline $\begin{array}{c}\text { Elasticity of } \\
\text { Substitution, } \eta\end{array}$ & $\beta_{1}$ & $\beta_{2}$ & $\beta_{3}$ & $\beta_{4}$ & $R^{2}$ \\
\hline 0.2 & -1.129 & 0.834 & -0.005 & -0.072 & 0.962 \\
0.5 & -0.978 & 0.768 & -0.022 & -0.065 & 0.974 \\
1.0 & -0.815 & 0.758 & -0.054 & -0.059 & 0.977 \\
1.5 & -0.774 & 0.683 & -0.070 & -0.053 & 0.973 \\
2.0 & -0.717 & 0.672 & -0.086 & -0.048 & 0.970 \\
\hline
\end{tabular}

the gain in fit associated with separately including the sectoral inflation rates and output gaps increases.

When the nominal rigidities are symmetric in the two sectors, the estimated parameter on durable sector inflation is large and positive while that on non-durable sector inflation is large and negative; the parameters on the output gaps are close to zero. As the degree of nominal rigidity in the durable sector falls, the coefficient on durable sector inflation rises somewhat while that on non-durable sector inflation becomes strongly positive. The coefficient on the non-durable sector output gap becomes sizable and positive while that on the durable sector output gap becomes quite negative.

\subsection{Various Elasticity of Substitution}

In all previous experiments, the parameter $\eta$, the elasticity of substitution between nondurable goods and durable goods, is set to 0.2 . This parameter value implies strong complementarity between non-durable goods and durable goods, and as shown in section 4.3, this strong complementarity is necessary to generate a boom in both the non-durable and durable goods sectors when agents expect a future technology improvement. This subsection explores how the estimated interest rate reaction function changes with the elasticity of substitution between non-durable and durable goods, with all other parameters are set to their baseline values.

Estimates of the simple policy rule Eq. (24) are summarized in Table 4. These experi- 
ments indicate that results obtained in the previous subsection are fairly robust to changes in the elasticity of substitution between non-durable and durable goods. As with the baseline parametrization, the rules estimated from the Ramsey policy data fit the model-simulated data well. Finally, as above, the estimated rules place a large, positive weight on durable sector inflation and a large, negative weight on non-durable sector inflation.

\subsection{What if the Central Bank Follows a Weakly Inflation Target Rule?}

Suppose that the central bank "weakly" targets inflation, using the interest rate rule,

$$
R_{t}=R_{s s}+1.01 \pi_{t}
$$

Further suppose that non-durable goods and durable goods are assumed are substitutes $(\eta=2)$. Recall from section 4.3 that the exogenous money supply rule cannot generate a boom in durable goods production in this case. Figure 5 shows the impulse responses of selected variables under both of the Ramsey policy and weakly inflation-targeting (WIT) rule defined in Eq. (27). The most interesting observation is that Pigou cycles can arise when the central bank follows WIT rule but again fails to arise when the central bank follows the Ramsey policy. In particular, a considerable boom in the durable good sector occurs under the WIT rule while the Ramsey policy requires a slight bust. The underlying mechanism is as follows: recall that non-durable goods and durable goods are assumed to be substitutes in this case; agents would rather postpone their accumulation of durable goods since they can be easily replaced by non-durable goods once the expected technology improvement is realized. However, a WIT rule is associated with a lower real interest rate in durable sector, and so a lower user cost, which spurs agents to accumulate durable goods. Figure 5 shows that a small difference in the real interest rate can cause a great difference in user cost. When

agents expect that the technology in the non-durable sector will improve in the future, they 
Figure 5: Responses to an Unrealized News Shock to the Non-durable Sector

(a) Non-durable Goods, $c$

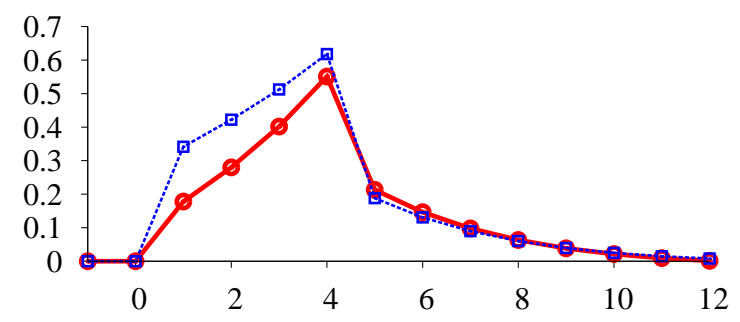

(c) Durables Production, $i$

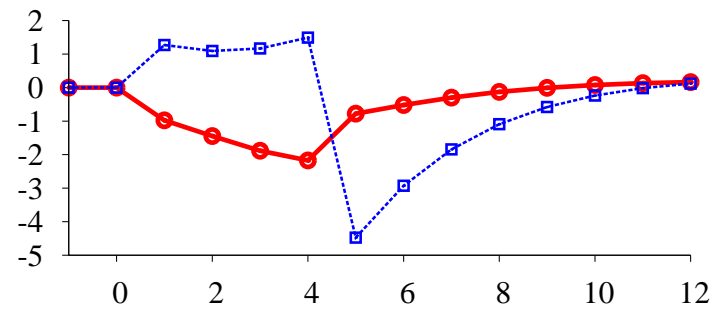

(e) Relative Price

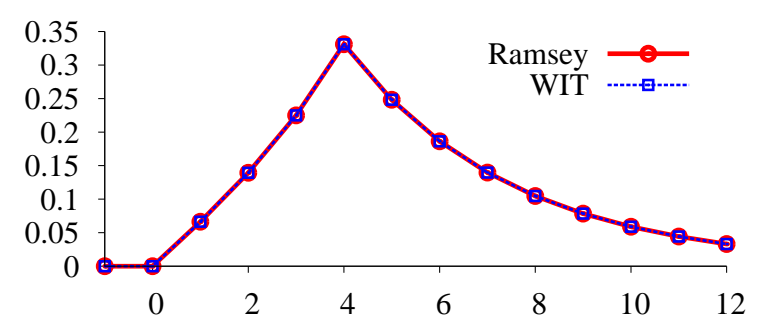

(g) Durables Sector Inflation

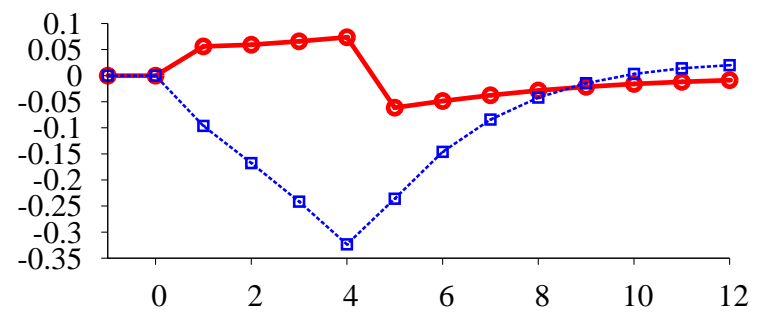

(i) Real Interest Rate, Durables

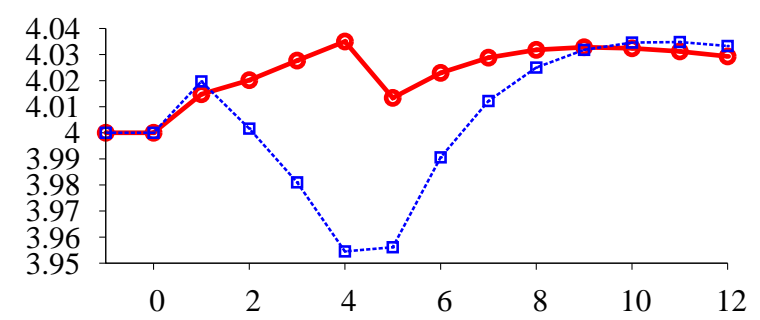

(b) Stock of Durables, $d$

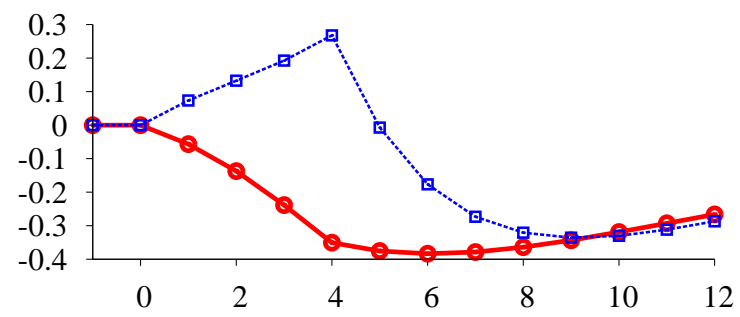

(d) Labor Supply

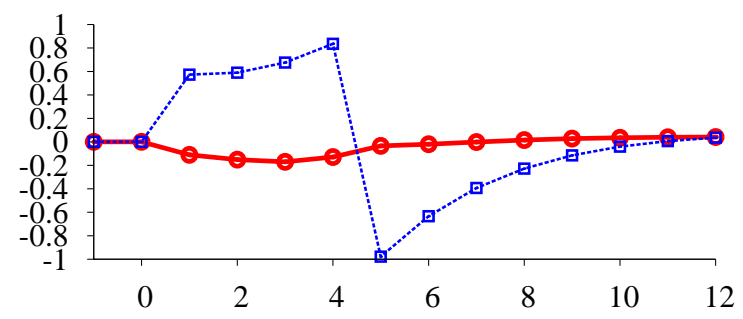

(f) Nominal Interest Rate

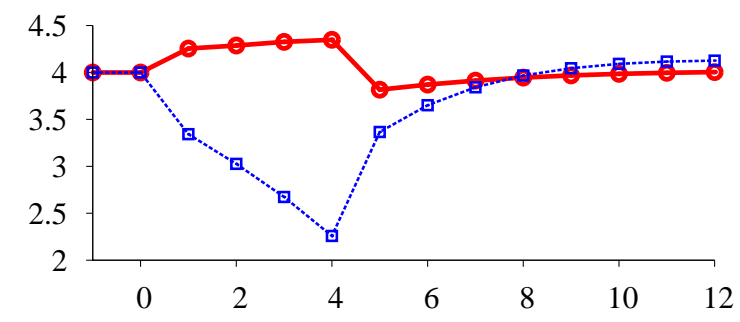

(h) Non-durable Sector Inflation

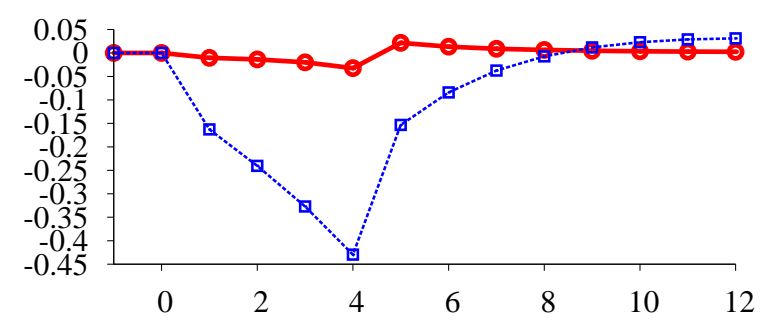

(j) User Cost

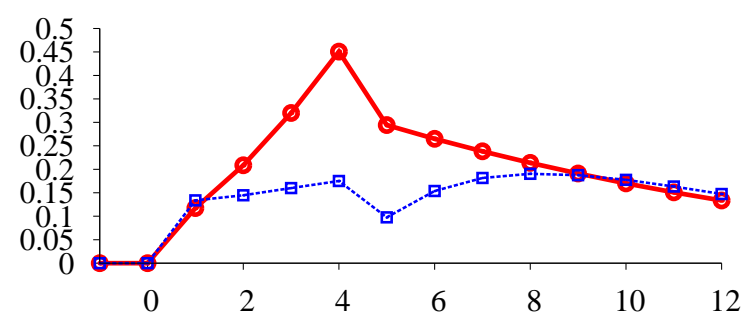


also expect that the relative price of durable goods will rise, which is associated with a chance to capture a capital gain. The higher real interest rate under the Ramsey policy dampens the discounted present value of the capital gain and depresses agents' incentives to capture the capital gain. By contrast, the lower real interest rate under WIT rule gives the agents more incentives to capture the expected capital gain by accumulating durable goods. The conclusion is that monetary policy can have a significant effect on the generation of Pigou cycles by affecting the real interest rate and user cost of durable goods. The assumption of a strong complementarity between non-durable goods and durable goods is no longer necessary to generate Pigou cycles when the monetary policy rule employed by the central bank fails to raise the real interest rate enough to dampen the incentives to accumulate durables to capture the capital gain.

\section{Conclusion}

In this paper, we have shown that monetary policy can lead to Pigou cycles, even when the Ramsey-optimal policy has no such dynamic. Specifically, news of a future productivity improvement in the non-durables sector leads to an immediate economic boom in both sectors of the economy, durables and non-durables; a general economic decline when this news is not realized. We showed that Pigou cycles can arise under an exogenous money supply rule when durables and non-durables are strong complements in utility - a standard condition in the Pigou cycle literature.

Interestingly, we also found that Pigou cycles can arise when durables and non-durables are highly substitutable if monetary policy follows a weak inflation targeting interest rate rule. What is common across the two specifications of monetary policy is a decline in the nominal interest rate upon receipt of the news shock, followed by a rise when the productivity improvement fails to materialize. In contrast, the Ramsey policy prescribes a rise in the nominal interest rate. As a result, the user cost of durables - an important determinant of 
durables purchases - rises far more sharply under the Ramsey policy, leading to a decline in durables purchases.

Nominal price rigidities are important in generating our results. Price adjustment à la Calvo (1983) implies that firms are forward looking in their price setting behavior. As a consequence, non-durable intermediate good producers start lowering their prices upon receipt of the news shock, and the relative price of durables rises. This dynamic is absent in the flexible price version of the model.

Finally, we estimated simple Taylor-style interest rate rules from model data generated under the Ramsey policy. These estimated interest rate rules have a high degree of fit with the artificial data, and their impulse-responses look quite similar to those obtained under the Ramsey policy. In other words, simple monetary policy rules - which can more easily be communicated to the public - can closely replicate the Ramsey-optimal policies. This last result complements work by Schmitt-Grohé and Uribe (2004). 


\section{A Summary of Equations Describing the Model Equi-}

\section{librium}

$$
\begin{aligned}
& -\frac{U_{n, t}}{U_{c, t}}=\hat{W}_{t} \\
& q_{t} U_{c, t}=U_{d, t}+\beta(1-\delta) E_{t}\left\{U_{c, t+1} q_{t+1}\right\} \\
& U_{c, t}=\beta E_{t}\left\{\frac{R_{t}}{\pi_{c, t+1}} U_{c, t+1}\right\} \\
& P 1_{j, t}=\omega_{j} \beta\left(\frac{\pi_{t+1}}{\pi}\right)^{\varepsilon_{j}} P 1_{j, t+1}+\lambda_{t} M C_{j, t} Y_{j, t} \hat{P}_{j, t}^{\varepsilon_{j}} \\
& P 2_{j, t}=\omega_{j} \beta\left(\frac{\pi_{t+1}}{\pi}\right)^{\varepsilon_{j}-1} P 2_{j, t+1}+\lambda_{t} Y_{j, t} \hat{P}_{j, t}^{\varepsilon_{j}-1} \\
& \hat{P}_{j, t}^{*}=\frac{P 1_{j, t}}{P 2_{j, t}} \\
& \hat{P}_{j, t}=\left[\left(1-\omega_{j}\right)\left(\hat{P}_{j, t}^{*}\right)^{1-\varepsilon_{j}}+\omega_{j}\left(\hat{P}_{j, t-1} \pi / \pi_{t}\right)^{1-\varepsilon_{j}}\right]^{\frac{1}{1-\varepsilon_{j}}} \\
& 1=(1-\alpha) \hat{P}_{c, t}^{1-\eta}+\alpha \hat{P}_{d, t}^{1-\eta} \\
& s_{c, t} Y_{c, t}=A_{c, t} N_{c, t}=s_{c, t} C_{t} \\
& s_{d, t} Y_{d, t}=A_{d, t} N_{d, t}=s_{d, t}\left(D_{t}-(1-\delta) D_{t-1}\right) \\
& s_{j, t}=\left(1-\omega_{j}\right)\left(\frac{\hat{P}_{j, t}^{*}}{\hat{P}_{j, t}}\right)^{-\varepsilon_{j}}+\omega_{j}\left(\frac{\pi}{\pi_{j, t}}\right)^{-\varepsilon_{j}} s_{j, t-1} \\
& N_{t}=N_{c, t}+N_{d, t} \\
& \hat{M}_{t}=C_{t}+q_{t}\left(D_{t}-(1-\delta) D_{t-1}\right) \\
& g_{t}=\pi_{c} \hat{M}_{t} / \hat{M}_{t-1} \\
& g_{t}=\rho_{g} g+\left(1-\rho_{g}\right) g_{t-1}+\xi_{t} \\
& \ln \left(A_{j, t}\right)=\rho_{j} \ln \left(A_{j, t-1}\right)+\varepsilon_{j, t-p}+\zeta_{j, t}
\end{aligned}
$$




\section{B The Ramsey Problem}

$$
\begin{aligned}
& \max E_{0} \sum_{t=0}^{\infty} \beta^{t}\left\{\ln \left(X_{t}\right)-v \frac{N_{t}^{1+\sigma}}{1+\sigma}\right. \\
& +\lambda_{1 t}\left(v N_{t}^{\sigma}-\hat{W}_{t} \lambda_{t}\right) \\
& +\lambda_{2 t}\left(X_{t}-\left[(1-\alpha)^{\frac{1}{\eta}} C_{t}^{\frac{\eta-1}{\eta}}+\alpha^{\frac{1}{\eta}} D_{t}^{\frac{\eta-1}{\eta}}\right]^{\frac{\eta}{\eta-1}}\right) \\
& +\lambda_{3 t}\left(X_{t}^{\frac{1-\eta}{\eta}}(1-\alpha)^{\frac{1}{\eta}} C_{t}^{-\frac{1}{\eta}}-\lambda_{t}\right) \\
& +\lambda_{4 t}\left(X_{t}^{\frac{1-\eta}{\eta}} \alpha^{\frac{1}{\eta}} D_{t}^{-\frac{1}{\eta}}+\beta(1-\delta) E_{t}\left\{\lambda_{t+1} q_{t+1}\right\}-q_{t} \lambda_{t}\right) \\
& +\lambda_{5 t}\left(1-\beta E_{t}\left\{\frac{R_{t}}{\pi_{c, t+1}} \frac{\lambda_{t+1}}{\lambda_{t}}\right\}\right) \\
& +\lambda_{6 t}\left(P 1_{c, t}-\omega_{c} \beta\left(\frac{\pi_{t+1}}{\pi}\right)^{\varepsilon_{c}} P 1_{c, t+1}+\lambda_{t} M C_{c, t} Y_{c, t} \hat{P}_{c, t}^{\varepsilon_{c}}\right) \\
& +\lambda_{7 t}\left(P 2_{c, t}-\omega_{c} \beta\left(\frac{\pi_{t+1}}{\pi}\right)^{\varepsilon_{c}-1} P 2_{c, t+1}+\lambda_{t} Y_{c, t} \hat{P}_{c, t}^{\varepsilon_{j}-1}\right) \\
& +\lambda_{8 t}\left(\hat{P}_{c, t}^{*}-\frac{P 1_{c, t}}{P 2_{c, t}}\right) \\
& +\lambda_{9 t}\left(\hat{P}_{c, t}^{1-\varepsilon_{c}}-\left[\left(1-\omega_{c}\right)\left(\hat{P}_{c, t}^{*}\right)^{1-\varepsilon_{c}}+\omega_{c}\left(\hat{P}_{c, t-1} \pi / \pi_{t}\right)^{1-\varepsilon_{c}}\right]\right) \\
& +\lambda_{10 t}\left(\pi_{c, t}-\pi_{t} \hat{P}_{c, t} / \hat{P}_{c, t-1}\right) \\
& +\lambda_{11 t}\left(P 1_{d, t}-\omega_{d} \beta\left(\frac{\pi_{t+1}}{\pi}\right)^{\varepsilon_{d}} P 1_{d, t+1}-\lambda_{t} M C_{d, t} I_{t} \hat{P}_{d, t}^{\varepsilon_{d}}\right) \\
& +\lambda_{12 t}\left(P 2_{d, t}-\omega_{d} \beta\left(\frac{\pi_{t+1}}{\pi}\right)^{\varepsilon_{d}-1} P 2_{d, t+1}-\lambda_{t} I_{t} \hat{P}_{d, t}^{\varepsilon_{d}-1}\right) \\
& +\lambda_{13 t}\left(\hat{P}_{d, t}^{*}-\frac{P 1_{d, t}}{P 2_{d, t}}\right) \\
& +\lambda_{14 t}\left(\hat{P}_{d, t}^{1-\varepsilon_{d}}-\left[\left(1-\omega_{d}\right)\left(\hat{P}_{d, t}^{*}\right)^{1-\varepsilon_{d}}+\omega_{d}\left(\hat{P}_{d, t-1} \pi / g_{t}\right)^{1-\varepsilon_{d}}\right]\right) \\
& +\lambda_{15 t}\left(\pi_{d, t}-\pi_{t} \hat{P}_{d, t} / \hat{P}_{d, t-1}\right) \\
& +\lambda_{16 t}\left(1-\left[(1-\alpha) \hat{P}_{c, t}^{1-\eta}+\alpha \hat{P}_{d, t}^{1-\eta}\right]\right) \\
& +\lambda_{17 t}\left(s_{c, t}-\left(1-\omega_{c}\right)\left(\frac{\hat{P}_{c, t}^{*}}{\hat{P}_{c, t}}\right)^{-\varepsilon_{j}}-\omega_{c}\left(\frac{\pi}{\pi_{c, t}}\right)^{-\varepsilon_{c}} s_{c, t-1}\right)
\end{aligned}
$$




$$
\begin{aligned}
& +\lambda_{18 t}\left(s_{d, t}-\left(1-\omega_{d}\right)\left(\frac{\hat{P}_{d, t}^{*}}{\hat{P}_{d, t}^{*}}\right)^{-\varepsilon_{j}}-\omega_{d}\left(\frac{\pi}{\pi_{d, t}}\right)^{-\varepsilon_{d}} s_{d, t-1}\right) \\
& +\lambda_{19 t}\left(M C_{c, t}-\frac{\hat{W}_{t}}{A_{c, t}}\right) \\
& +\lambda_{20 t}\left(M C_{d, t}-\frac{\hat{W}_{t}}{A_{c, t} q_{t}}\right) \\
& +\lambda_{21 t}\left(s_{c, t} C_{t}-A_{c, t} N_{c, t}\right) \\
& +\lambda_{22 t}\left(s_{d, t}\left(D_{t}-(1-\delta) D_{t-1}\right)-A_{d, t} N_{d, t}\right) \\
& +\lambda_{23 t}\left(I_{t}-D_{t}+(1-\delta) D_{t-1}\right) \\
& +\lambda_{24 t}\left(N_{t}-N_{c t}-N_{d t}\right) \\
& \left.+\lambda_{25 t}\left(q_{t}-\hat{P}_{d, t} / \hat{P}_{c t}\right)\right\}
\end{aligned}
$$

\section{First Order Conditions of the Ramsey Problem}

$$
\begin{aligned}
C_{t}: \quad & -\lambda_{2 t} X_{t}^{\frac{1}{\eta}}(1-\alpha)^{\frac{1}{\eta}} C_{t}^{-\frac{1}{\eta}}-\lambda_{3 t} X_{t}^{\frac{1-\eta}{\eta}}(1-\alpha)^{\frac{1}{\eta}}\left(\frac{1}{\eta}\right) C_{t}^{-\frac{1}{\eta}-1}-\lambda_{6 t} \lambda_{t} M C_{c t} \hat{P}_{c, t}^{\varepsilon_{c}}=0 \\
& -\lambda_{7 t} \lambda_{t} \hat{P}_{c, t}^{\varepsilon_{c}-1}+\lambda_{21} s_{c, t} \\
D_{t}: \quad & -\lambda_{2 t} X_{t}^{\frac{1}{\eta}} \alpha^{\frac{1}{\eta}} D_{t}^{-\frac{1}{\eta}}-\lambda_{4 t} X_{t}^{\frac{1-\eta}{\eta}} \alpha^{\frac{1}{\eta}}\left(\frac{1}{\eta}\right) D_{t}^{-\frac{1}{\eta}-1}+\lambda_{22 t} s_{d, t}-\beta \lambda_{22 t+1} s_{d, t+1}(1-\delta) \\
& -\lambda_{23 t}+\beta \lambda_{23 t+1}(1-\delta)=0 \\
I_{t}: \quad & -\lambda_{11 t} \lambda_{t} M C_{d, t} \hat{P}_{d, t}^{\varepsilon_{d}}-\lambda_{12 t} \lambda_{t} \hat{P}_{d, t}^{\varepsilon_{d}-1}+\lambda_{23 t}=0 \\
\lambda_{t}: \quad & -\lambda_{1 t} \hat{W}_{t}-\lambda_{3 t}-\lambda_{4 t} q_{t}+\frac{1}{\beta} \lambda_{4 t-1} \beta(1-\delta) q_{t}+\lambda_{5 t} \beta \frac{R_{t}}{\pi_{c, t+1}} \frac{\lambda_{t+1}}{\lambda_{t}^{2}}-\frac{1}{\beta} \lambda_{5 t-1} \beta \frac{R_{t-1}}{\pi_{c, t}} \frac{1}{\lambda_{t-1}} \\
& -\lambda_{6 t} M C_{c, t} C_{t} \hat{P}_{c, t}^{\varepsilon_{c}}-\lambda_{7 t} C_{t} \hat{P}_{c, t}^{\varepsilon_{c}-1}-\lambda_{11 t} M C_{d, t} I_{t} \hat{P}_{d, t}^{\varepsilon_{d}}-\lambda_{12 t} I_{t} \hat{P}_{d, t}^{\varepsilon_{d}-1}=0 \\
M C_{c t}: \quad & -\lambda_{6 t} \lambda_{t} C_{t} \hat{P}_{c, t}^{\varepsilon_{c}}+\lambda_{19 t}=0 \\
M C_{d t}: \quad & -\lambda_{11 t} \lambda_{t} M C_{d, t} I_{t} \hat{P}_{d, t}^{\varepsilon_{d}}+\lambda_{20 t}=0 \\
N_{t}: \quad & -v N_{t}^{\sigma}+\lambda_{1 t} v \sigma N_{t}^{\sigma-1}+\lambda_{24 t}=0 \\
N_{c t}: \quad & -\lambda_{21 t} A_{c t}-\lambda_{24 t}=0
\end{aligned}
$$


$N_{d t}: \quad-\lambda_{22 t} A_{d t}-\lambda_{24 t}=0$

$P 1_{c t}: \quad \lambda_{6 t}-\frac{1}{\beta} \lambda_{6 t-1} \omega_{c} \beta\left(\frac{\pi_{t}}{\pi}\right)^{\varepsilon_{c}}-\frac{\lambda_{8 t}}{P 2_{c, t}}=0$

$P 1_{d t}: \quad \lambda_{11 t}-\frac{1}{\beta} \lambda_{11 t-1} \omega_{d} \beta\left(\frac{\pi_{t}}{\pi}\right)^{\varepsilon_{d}}-\frac{\lambda_{13 t}}{P 2_{d, t}}=0$

$P 2_{c t}: \quad \lambda_{7 t}-\frac{1}{\beta} \lambda_{7 t-1} \omega_{c} \beta\left(\frac{\pi_{t}}{\pi}\right)^{\varepsilon_{c}-1}+\lambda_{8 t} \frac{P 1_{c, t}}{P 2_{c, t}^{2}}=0$

$P 2_{d t}: \quad \lambda_{12 t}-\frac{1}{\beta} \lambda_{12 t-1} \omega_{d} \beta\left(\frac{\pi_{t}}{\pi}\right)^{\varepsilon_{d}-1}+\lambda_{13 t} \frac{P 1_{d, t}}{P 2_{d, t}^{2}}=0$

$\hat{P}_{c t}: \quad-\lambda_{6 t} \lambda_{t} M C_{c, t} C_{t} \hat{P}_{c, t}^{\varepsilon_{c}-1} \varepsilon_{c}-\lambda_{7 t} \lambda_{t} C_{t} \hat{P}_{c, t}^{\varepsilon_{c}-2}\left(\varepsilon_{c}-1\right)+\lambda_{9 t}\left(1-\varepsilon_{c}\right)\left(\hat{P}_{c t}\right)^{-\varepsilon_{c}}$

$-\beta \lambda_{9 t+1} \omega_{c}\left(\hat{P}_{c, t} \pi / \pi_{t}\right)^{1-\varepsilon_{c}}\left(1-\varepsilon_{c}\right)\left(\frac{1}{\hat{P}_{c t}}\right)$

$-\lambda_{10 t} \pi_{t} / \hat{P}_{c, t-1}+\beta \lambda_{10 t+1} \pi_{t+1} \hat{P}_{c, t+1} / \hat{P}_{c, t}^{2}-\lambda_{16 t}(1-\alpha)(1-\eta) \hat{P}_{c, t}^{-\eta}+\lambda_{25 t} \frac{\hat{P}_{d t}}{\hat{P}_{c t}^{2}}=0$

$\hat{P}_{d t}: \quad-\lambda_{12 t} \lambda_{t} M C_{d, t} I_{t} \hat{P}_{d, t}^{\varepsilon_{d}-1} \varepsilon_{d}-\lambda_{12 t} \lambda_{t} I_{t} \hat{P}_{d, t}^{\varepsilon_{d}-2}\left(\varepsilon_{d}-1\right)+\lambda_{14 t}\left(1-\varepsilon_{d}\right)\left(\hat{P}_{d t}\right)^{-\varepsilon_{d}}$

$-\beta \lambda_{14 t+1} \omega_{d}\left(\hat{P}_{d, t} \pi / \pi_{t}\right)^{1-\varepsilon_{d}}\left(1-\varepsilon_{d}\right)\left(\frac{1}{\hat{P}_{d t}}\right)$

$-\lambda_{15 t} \pi_{t} / \hat{P}_{d, t-1}+\beta \lambda_{15 t+1} \pi_{t+1} \hat{P}_{d, t+1} / \hat{P}_{d, t}^{2}-\lambda_{16 t} \alpha(1-\eta) \hat{P}_{d, t}^{-\eta}+\frac{\lambda_{25 t}}{\hat{P}_{c t}}=0$

$\pi_{t}: \quad-\frac{1}{\beta} \lambda_{6 t-1} \omega_{c} \beta P 1_{c t}\left(\frac{\pi_{t}}{\pi}\right)^{\varepsilon_{c}} \frac{\varepsilon_{c}}{\pi_{t}}-\frac{1}{\beta} \lambda_{7 t-1} \omega_{c} \beta P 2_{c t}\left(\frac{\pi_{t}}{\pi}\right)^{\varepsilon_{c}-1} \frac{\varepsilon_{c}-1}{\pi_{t}}+\lambda_{9 t} \omega_{c}\left(\hat{P}_{c, t-1} \pi / \pi_{t}\right)^{1-\varepsilon_{c}}\left(1-\varepsilon_{c}\right) \frac{1}{\pi_{t}}$

$-\lambda_{10 t} \hat{P}_{c, t} / \hat{P}_{c, t-1}-\frac{1}{\beta} \lambda_{11 t-1} \omega_{d} \beta P 1_{d t}\left(\frac{\pi_{t}}{\pi}\right)^{\varepsilon_{d}} \frac{\varepsilon_{d}}{\pi_{t}}-\frac{1}{\beta} \lambda_{12 t-1} \omega_{d} \beta P 2_{d t}\left(\frac{\pi_{t}}{\pi}\right)^{\varepsilon_{d}-1} \frac{\varepsilon_{d}-1}{\pi_{t}}$

$+\lambda_{14 t} \omega_{d}\left(\hat{P}_{d, t-1} \pi / \pi_{t}\right)^{1-\varepsilon_{d}}\left(1-\varepsilon_{d}\right) \frac{1}{\pi_{t}}-\lambda_{15 t} \hat{P}_{d, t} / \hat{P}_{d, t-1}=0$

$\pi_{c t}: \quad \frac{1}{\beta} \lambda_{5, t-1} \beta R_{t-1} \frac{\lambda_{t}}{\lambda_{t-1} \pi_{c t}^{2}}+\lambda_{10 t}-\lambda_{17 t} \omega_{c}\left(\frac{\pi}{\pi_{c, t}}\right)^{-\varepsilon_{c}}\left(\frac{\varepsilon_{c}}{\pi_{c, t}}\right) s_{c, t-1}=0$

$\pi_{d t}: \quad \lambda_{15 t}-\lambda_{18 t} \omega_{d}\left(\frac{\pi}{\pi_{d, t}}\right)^{-\varepsilon_{d}}\left(\frac{\varepsilon_{d}}{\pi_{d, t}}\right) s_{d, t-1}=0$

$\hat{P}_{c t}^{*}: \quad \lambda_{8 t}+\lambda_{9 t}\left(\omega_{c}-1\right) \hat{P}_{c t}^{*-\varepsilon_{c}}\left(1-\varepsilon_{c}\right)+\lambda_{17 t} \varepsilon_{c}\left(1-\omega_{c}\right)\left(\frac{\hat{P}_{c t}^{*}}{\hat{P}_{c t}}\right)^{-\varepsilon_{c}-1}\left(\frac{1}{\hat{P}_{c t}}\right)=0$

$\hat{P}_{d t}^{*}: \quad \lambda_{13 t}+\lambda_{14 t}\left(\omega_{d}-1\right) P_{d t}^{*-\varepsilon_{d}}\left(1-\varepsilon_{d}\right)+\lambda_{18 t} \varepsilon_{d}\left(1-\omega_{d}\right)\left(\frac{\hat{P}_{d t}^{*}}{\hat{P}_{d t}}\right)^{-\varepsilon_{d}-1}\left(\frac{1}{\hat{P}_{d t}}\right)=0$

$q_{t}: \quad-\lambda_{4 t} \lambda_{t}+\frac{1}{\beta} \lambda_{4 t-1} \beta(1-\delta) \lambda_{t}+\lambda_{20 t} \hat{W}_{t} / A_{d t} q_{t}^{2}+\lambda_{25 t}=0$

$R_{t}: \quad-\lambda_{5 t} \beta \frac{\lambda_{t+1}}{\lambda_{t} \pi_{c t+1}}=0$ 


$$
\begin{array}{ll}
s_{c, t}: \quad \lambda_{17 t}-\beta \lambda_{17 t+1} \omega_{c}\left(\frac{\pi}{\pi_{c, t+1}}\right)^{-\varepsilon_{c}}+\lambda_{21 t} C_{t}=0 \\
s_{d, t}: \quad \lambda_{18 t}-\beta \lambda_{18 t+1} \omega_{d}\left(\frac{\pi}{\pi_{d, t+1}}\right)^{-\varepsilon_{d}}+\lambda_{22 t}\left(D_{t}-(1-\delta) D_{t-1}\right)=0 \\
\hat{W}_{t}: \quad-\lambda_{1 t} \lambda_{t}-\frac{\lambda_{19 t}}{A_{c t}}-\frac{\lambda_{20 t}}{A_{d t} q_{t}}=0 \\
X_{t}: \quad X_{t}^{-1}+\lambda_{2 t}+\lambda_{3 t} \frac{1-\eta}{\eta} X_{t}^{\frac{1-2 \eta}{\eta}}(1-\alpha)^{\frac{1}{\eta}} C_{t}^{-\frac{1}{\eta}}+\lambda_{4 t} \frac{1-\eta}{\eta} X_{t}^{\frac{1-2 \eta}{\eta}} \alpha^{\frac{1}{\eta}} D_{t}^{-\frac{1}{\eta}}=0
\end{array}
$$




\section{References}

Aoki, Kosuke (2001). "Optimal Monetary Policy Responses to Relative-Price Changes," Journal of Monetary Economics, 48 (1): 55-80.

Barsky, Robert, Christopher L. House and Miles Kimball (2007). "Sticky Price Models and Durable Goods," American Economic Review, 97 (3): 984-998.

Beaudry, Paul and Franck Portier (2004). "An Exploration Into Pigou's Theory of Cycles," Journal of Monetary Economics, 51 (6): 1183-1216.

Benigno, Pierpaolo (2004). "Optimal Monetary Policy in a Currency Area," Journal of International Economics, 63 (2): 293-320.

Bils, Mark and Peter J. Klenow (2004). "Some Evidence on the Importance of Sticky Prices," Journal of Political Economy, 112 (5): 947-985.

Calvo, Guillermo (1983). "Staggered Prices in a Utility Maximizing Framework," Journal of Monetary Economics, 12 (3): 383-398.

Christiano, Lawrence, Cosmin Ilut, Roberto Motto and Massimo Rostagno (2008). "Monetary Policy and Stock Market Boom-Bust Cycles," European Central Bank Working Paper No. 955.

Erceg, Christopher and Andrew Levin (2006). "Optimal Monetary Policy with Durable Consumption Goods," Journal of Monetary Economics, 53 (7): 1341-1359.

Gomme, Paul and Peter Rupert (2007). "Theory, Measurement and Calibration of Macroeconomic Models," Journal of Monetary Economics, 54 (2): 460-97.

Jaimovich, N. and Sergio Rebelo (forthcoming). "Can News About the Future Drive the Business Cycle?" American Economic Review.

Khan, Aubhik, Robert G. King and Alexander L. Wolman (2003). "Optimal Monetary Policy," Review of Economic Studies, 70 (4): 825-860. 
Levin, Andrew T., Alexei Onatski, John C. Williams and Noah Williams (2006). "Monetary Policy Under Uncertainty in Micro-Founded Macroeconometric Models," in Mark Gertler and Kenneth Rogoff, eds., "NBER Macroeconomics Annual 2005," MIT Press, Cambridge, pp. 229-287.

Monacelli, Tommaso (2008). "Optimal Monetary Policy with Collateralized Household Debt and Borrowing Constraints," in John Y. Campbell, ed., "Asset Prices and Monetary Policy," University of Chicago Press.

Monacelli, Tommaso (2009). "New Keynesian Models, Durable Goods, and Collateral Constraints," Journal of Monetary Economics, 56 (2): 242-254.

Prescott, Edward C. (1986). "Theory Ahead of Business Cycle Measurement," Federal Reserve Bank of Minneapolis Quarterly Review, 10 (4): 9-22.

Rotemberg, Julio and Michael Woodford (1997). "An Optimization-Based Econometric Framework for the Evaluation of Monetary Policy," in Ben Bernanke and Julio J. Rotemberg, eds., "NBER Macroeconomics Annual 1997," Cambridge and London: MIT Press, pp. 297-346.

Schmitt-Grohé, Stephanie and Martn Uribe (2004). "Optimal Fiscal and Monetary Policy under Sticky Prices," Journal of Economic Theory, 114 (2): 198-230.

Siu, Henry E. (2004). "Optimal Fiscal and Monetary Policy with Sticky Prices," Journal of Monetary Economics, 51 (3): 575-607.

Taylor, John B. (1993). "Discretion Versus Policy Rules in Practice," Carnegie-Rochester Series on Public Policy, 39 (1): 195-214.

Taylor, John B. (1999). "Staggered Price and Wage Setting in Macroeconomics," in J. B. Taylor and M. Woodford, eds., "Handbook of Macroeconomics," North-Holland, Amsterdam, New York. 